\title{
Strategien zur Sedimentbewertung - ein Überblick
}

\author{
Henner Hollert • Marit Ernst • Wolfgang Ahlf • Matthias Dürr · Lothar Erdinger · Stefanie Grund · Steffen Keiter · \\ Thomas Kosmehl · Thomas-Benjamin Seiler · Jan Wölz $\cdot$ Thomas Braunbeck
}

Eingegangen: 13. Januar 2009/Akzeptiert: 23. Februar 2009/Online veröffentlicht: 20. März 2009

(C) Springer-Verlag 2009

Zusammenfassung Hintergrund Sedimente sind als wichtiger Faktor bei der Beurteilung der Gewässerqualität in den letzten Jahren stärker in die wissenschaftliche und öffentliche Diskussion geraten. Während sich die Wasserqualität in den letzten Jahren deutlich verbessert hat, werden zum Teil hoch kontaminierte Sedimente in vielen europäischen Einzugsgebieten die Gewässerqualität noch für viele Jahrzehnte nachhaltig beeinflussen. Monitoring und Bewertung

Dieser Beitrag ist Herrn Prof. Dr. Dr. h.c. Volker Storch zum 65. Geburtstag gewidmet, der die Aachener und Heidelberger Autoren dieses Artikels zunächst durch seine hervorragende Lehre für Zoologie und Ökologie begeistert hat und in der Forschung durch seine stete Unterstützung die Sedimenttoxikologie als eigene Forschungsrichtung an seinem Institut hat wachsen lassen.

Herausgeber: Henner Hollert · Thomas Braunbeck

H. Hollert $(\bowtie) \cdot$ M. Ernst · T.-B. Seiler $\cdot$ J. Wölz

Institut für Umweltforschung (Biologie V), Lehr- und

Forschungsgebiet für Ökosystemanalyse,

Rheinisch-Westfälische Technische Hochschule Aachen,

Worringerweg 1, 52074 Aachen, Deutschland

E-Mail: henner.hollert@bio5.rwth-aachen.de

T. Braunbeck · T. Kosmehl $\cdot$ S. Keiter $\cdot$ S. Grund

Aquatische Ökologie und Toxikologie, Institut für Zoologie,

Universität Heidelberg, Im Neuenheimer Feld 230,

69120 Heidelberg, Deutschland

W. Ahlf

TU Hamburg-Harburg, Umwelttechnik und Energiewirtschaft, Eißendorfer Straße 40, 21073 Hamburg, Deutschland

\section{Erdinger}

Hygiene Institut der Universität Heidelberg, Abt. Hygiene und Med. Mikrobiologie, Im Neuenheimer Feld 324,

69120 Heidelberg, Deutschland

\section{Dürr}

Institut für Hygiene,

Johann-Andreas-Segner-Str. 12, 06108 Halle (Saale), Deutschland der Sedimentqualität kommen daher nicht nur im Rahmen nationalen Rechts, sondern auch bei der Umsetzung der europäischen Wasserrahmenrichtlinie große Bedeutung zu. Ziel In diesem Beitrag soll ein Überblick über verschiedene Konzepte zur Bewertung von Sedimenten gegeben werden. Ein weiterer Schwerpunkt des Beitrages, der in einem Sonderheft anlässlich der Emeritierung von Prof. Dr. Dr. h.c. Volker Storch erscheint, liegt auf der exemplarischen Vorstellung von Fallstudien zur Sedimenttoxikologie, die jeweils im Heidelberger Umfeld entstanden sind.

Ergebnisse und Diskussion In diesem Übersichtsartikel werden zunächst die Vor- und Nachteile von chemischer Analytik und Biotestverfahren hinsichtlich der Sedimentbewertung dargestellt. Während jede Methodik für sich gesehen nur begrenzte Aussagekraft hat, ermöglicht deren Kombination eine umfassende Charakterisierung des Sedimentzustandes. In diesem Kontext werden Stufenverfahren und integrierte Sedimentbewertungen mittels Weightof-Evidence-Studien vorgestellt. Als zusätzliches Konzept wird die Effekt-dirigierte Analyse präsentiert, bei der über die Kombination aus Fraktionierungen, biologischen Wirktests und nachfolgenden chemischen Analysen letztendlich die biologisch problematischen Substanzklassen oder gar Substanzen identifiziert werden können. Weiterhin wird dargestellt, dass bei der weiteren Umsetzung der Wasserrahmenrichtlinie auch die Sedimentmobilität für die Risikoanalyse von teils hochbelasteten Altsedimenten eine Rolle spielen wird.

Ausblick An verschiedenen Fallbeispielen wird in dem Artikel verdeutlicht, dass insbesondere das Konzept der Effektdirigierten Analysen, der kombinierte Einsatz von akuten und Mechanismus-spezifischen Biotestverfahren, In-situUntersuchungen in Weight-of-Evidence-Studien sowie die kombinierte Untersuchung von Sedimentbelastung und -mobilität ein großes Potenzial für die Kausalanalyse von 
komplexen Umweltproblemen in aquatischen Systemen und für die Maßnahmenprogramme in den Bewirtschaftungsplänen chemisch belasteter Flüsse besitzen.

Schlüsselwörter Effekt-dirigierte Analyse · Hochwasser · Schwebstoffe $\cdot$ Sediment $\cdot$ Toxizität $\cdot$ Weight-of-Evidence

\section{Strategies for assessing sediment toxicity - a review}

Abstract Background Being an important determinant in aquatic ecosystems, sediments have gotten more and more into focus of scientific and public discussions. While water quality has been significantly improving during recent years, highly contaminated sediments in many European rivers will still have ongoing impact for several centuries from now. Hence, monitoring and assessment of sediment quality are crucial for national legislation as well as the implementation of the European Water Framework Directive (WFD).

Aim On the occasion of the retirement of Prof. Dr. Dr. h.c. Volker Storch, this article reviews the various concepts of sediment assessment and introduces case studies in sediment toxicology which have been carried out in Heidelberg and surrounding areas.

Results and Discussion Initially, the article portrays benefits and drawbacks of chemical analytics and biotest systems. The individual approach has only limited informative value, but combining both perspectives allows for a comprehensive characterization of the state of sediments. As examples of toxicity evaluation based on this strategy, weight-of-evidence studies for tiered investigations and integrated sediment assessment are presented. In addition, a combination of chemical fractionation, bioanalytic investigations and chemical analysis - known as 'effect-directed analysis' (EDA) - is discussed. This integrated concept eventually aims at the identification of hazardous substance classes or even of single compounds. Finally, the article raises the issue of sediment mobility as an important parameter for risk analyses of highly contaminated legacy sediments within further WFD implementation.

Outlook Using various case studies, the article outlines the potentials of integrated approaches for cause-effect analysis of complex environmental samples within aquatic ecosystems as well as for action programs of management plans dealing with chemically polluted rivers. Effect-directed analysis in particular, but also the combined application of acute and mechanism-specific bioassays together with in-situ investigations, complemented by investigations on sediment mobility, appear promising with regard to comprehensive sediment assessment weight-of-evidence studies.

Keywords Effect-directed analysis - Flood events · Suspended particulate matter $\cdot$ Sediment $\cdot$ Toxicity . Weight-of-Evidence

\section{Problemstellung}

Die EU-Wasserrahmenrichtlinie (WRRL - European Water Framework Directive, EWFD) zielt darauf ab, für oberirdische Gewässer in europäischen Einzugsgebieten bis zum Jahr 2015 einen guten ökologischen und chemischen $\mathrm{Zu}$ stand zu erreichen. Die dafür erforderliche Reduzierung der Gewässerbelastung durch anthropogene Schadstoffe aus diffusen und Punktquellen soll in einem kombinierten Ansatz über die Vorgabe von Emissionsgrenzwerten und immissionsorientierten Qualitätszielen erreicht werden (Förstner 2002; Hollert et al. 2007c).

Sedimente stellen eine wichtige Determinante der Gewässerqualität in aquatischen Systemen dar: Sie können sowohl Senke für wassergelöste Schadstoffe als auch unter bestimmten Umständen Schadstoffquelle sein (Ahlf et al. 2002b; Förstner und Müller 1974). Insbesondere durch das europäische Netzwerk SedNet und durch die SETAC Nordamerika (Wenning und Ingersoll 2002) sind Sedimente in den letzten Jahren stärker in die wissenschaftliche und öffentliche Diskussion gerückt. Zahlreiche internationale Studien konnten einen Zusammenhang zwischen Sedimentbelastung und Schädigungen von Biozönosen von Wirbellosen und auch eine Häufung von Tumoren in Fischen nachweisen (für Übersichten siehe Chen und White 2004; White et al. 1998a,b).

Inzwischen hat ein Paradigmenwechsel stattgefunden; Sedimente werden nicht nur als ein (zumeist problembeladenes) Gewässerkompartiment aufgefasst; vielmehr setzt sich eine holistische Sichtweise durch, bei der Sedimente im Global-Change-Kontext (Salomons 2005) wie auch als wichtige Ressource (SedNet 2004) verstanden werden: Sedimente sind z. B. auch ein wichtiges Habitat für Organismen sowie eine Nährstoffquelle für Organismen und Landwirtschaft, so dass ein nachhaltiges Sedimentmanagement zunehmend an Bedeutung gewinnen wird.

Während sich die Wasserqualität durch den technischen Gewässerschutz in den letzten Jahren deutlich verbessert hat, stellen zum Teil hoch kontaminierte Sedimente in vielen europäischen Einzugsgebieten ein Vermächtnis der vergangenen industriellen Ära dar, das die Gewässerqualität noch für viele Jahrzehnte nachhaltig beeinflussen wird (SedNet 2004). Sedimentgebundene Schadstoffe können durch Bioturbation (Power und Chapman 1992), Hochwasserereignisse (Hollert et al. 2000, 2003b) oder Verklappung von Sedimenten (Koethe 2003) remobilisiert werden. Aus diesem Grunde hat das Monitoring und die Bewertung der Sedimentqualität nicht nur im Rahmen nationalen Rechts, sondern auch bei der Umsetzung der europäischen Wasserrahmenrichtlinie eine große Bedeutung (SedNet 2004).

In diesem Beitrag soll ein Überblick über verschiedene Konzepte zur Bewertung von Sedimenten gegeben werden. Ein Schwerpunkt des Beitrages, der in dem vorliegenden 
Sonderheft anlässlich der Emeritierung von Prof. Dr. Dr. h. c. Volker Storch erscheinen soll, liegt auch auf der exemplarischen Vorstellung von Fallstudien zur Sedimenttoxikologie, die jeweils im Heidelberger Umfeld entstanden sind.

\section{Chemische Analysen}

Historisch wurde zunächst mit chemisch-analytischen Methoden nachgewiesen, dass Sedimente, besonders nach Einleitung von hochkontaminierten Abwässern, lipophile Schadstoffe anreichern und bei Sedimentation oder Umlagerung auf landwirtschaftlichen Flächen ein wichtiger Eintragspfad in die Nahrungskette sein können. Insbesondere an den großen amerikanischen Seen, aber auch an den Flüssen Elbe und Neckar in der Bundesrepublik konnten ab den 1970er-Jahren hohe Belastungen der Sedimente mit organischen und anorganischen Schadstoffen nachgewiesen werden (Förstner und Müller 1974). Auch heute hat die chemische Analytik in der Sedimentbewertung eine immense Bedeutung, sei es bei der Identifizierung neuer Problemverbindungen (z. B. Perfluorverbindungen; Giesy und Kannan 2002) oder hinsichtlich des Monitorings von prioritären Schadstoffen: Durch die von der Europäischen Kommission veröffentlichte Tochterdirektive der WRRL wird erstmals das Monitoring der Sedimentqualität reguliert. Der neue Artikel 2 (2) fordert, dass die Mitgliedstaaten dafür Sorge tragen, dass die Konzentrationen von 33 prioritären Schadstoffen (Anhang I, Teile A und B, vgl. dort Tabelle 2) in Sedimenten und Organismen nicht ansteigen (EC 2006; Hollert et al. 2007b).

Obwohl der Biotestansatz bei den Strategien zur Bewertung von Sedimenten und Schwebstoffen in den letzten Jahren immer wichtiger wurde, dominiert in der Bundesrepublik Deutschland noch immer der chemisch-numerische Ansatz (Ahlf 1995; Gratzer und Ahlf 1999a; Henschel et al. 2001; Hollert et al. 1999f; Neumann-Hensel et al. 2000a). Eine rein chemisch-analytische Unterscheidung gefährlicher von nicht gefährlichen Sedimenten erscheint jedoch in Anbetracht der Vielzahl bekannter sedimentassoziierter Verbindungen und des limitierten Wissens über deren toxische Wirkung nur in einem sehr begrenzten Maße möglich (Ahlf et al. 1991). Für eine Bewertung von Sedimenten und Schwebstoffen sind vielmehr biologische Wirkungstests notwendig, um summarisch die Wirkung aller Inhaltsstoffe zu erfassen, sowie deren synergistische und antagonistische Effekte (Verstärkung oder Reduzierung der toxischen Wirkung von Stoffgemischen) und Metabolisierung im Organismus (Toxifizierung und Detoxifizierung) zu berücksichtigen (Burton 1991, 1995; Gunkel 1994). Somit kann eine ökotoxikologische Bewertung der Sedimentqualität nur mittels einer Kombination von standardisierten chemischen und biologischen Testverfahren erfolgen (Förstner et al. 1989; Neumann-Hensel et al. 2000a).

\section{Biotests zum Nachweis von Sedimenttoxizität}

Sedimenttoxizität ist nach Ahlf (1995) im weitesten Sinn definiert als „ökologische und biologische Änderung, die durch kontaminiertes Sediment verursacht wird. Sie kann auch operational bestimmt werden als die negative Wirkung an einem Testorganismus, der einem belasteten Sediment ausgesetzt wurde." Sedimentgebundene Schadstoffe verursachen zahlreiche in der Literatur gut belegte biologische Wirkungen (Übersichten bei Ahlf 1995; Burton 1991, 1995; Ingersoll et al. 1997; Zimmer und Ahlf 1994): auf organismischer Ebene Mortalität, erbgutverändernde, endokrine und pathologische Effekte, auf der Populationsebene Änderungen in Abundanzen und Diversität sowie auf biozönotischer Ebene Änderungen in Struktur und Funktion (Ahlf 1995). Die Schadwirkung partikulär gebundener Stoffe kann daher auf verschiedenen Organisationsebenen untersucht werden (Abb. 1). Dabei findet jede Organisationsebene ihre mechanistische Erklärung auf der nächst-niederen Organisationsebene. So resultiert eine Beeinträchtigung des Reproduktionserfolgs einer bestimmten Art etwa aus einer Reihe von Schädigungen auf dem Niveau der Organe. Diese sind Folge von Schädigungen auf zellulärem Niveau und lassen sich wiederum auf molekulare Mechanismen zurückführen (Braunbeck et al. 1995b). Von größter ökologischer Relevanz sind in diesem Zusammenhang Untersuchungen, die Veränderungen von Strukturen und Funktionen von
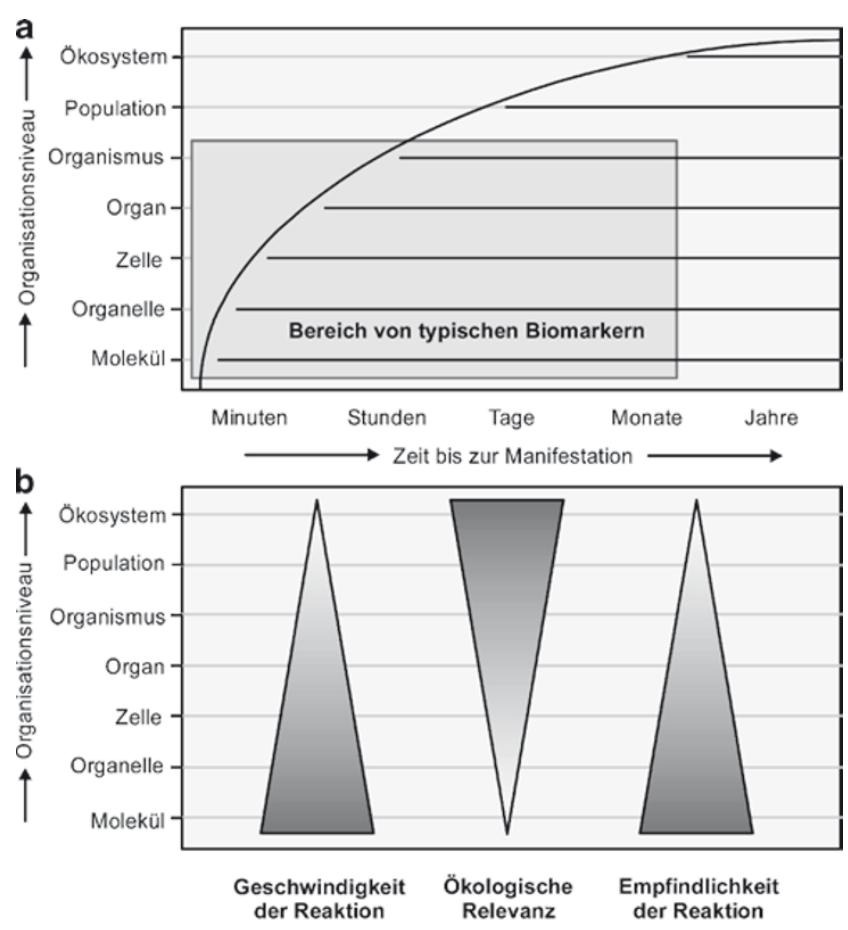

Abb. 1 Die Schadwirkung partikulär gebundener Stoffe kann auf verschiedenen Organisationsebenen untersucht werden 
Ökosystemen unter dem Einfluss von kontaminierten Sedimenten analysieren. Funktionell gesehen ist dagegen der Angriffspunkt von Sedimentschadstoffen auf molekularer Ebene und strukturell auf dem Niveau von Zellorganellen und Zellen zu suchen. Der hohen ökologischen Relevanz von Untersuchungen auf Populations- und Ökosystemniveau stehen somit die Vorteile von Untersuchungen auf niedrigerer Ebene in Form von erhöhter Geschwindigkeit und größerer Empfindlichkeit gegenüber (Burton 1991).

Prokaryontische Testverfahren (mit Bakterien) und Tests an Invertebraten für die Bewertung von Sedimenten werden mittlerweile insbesondere im angelsächsischen Raum häufig verwendet (Übersichten bei Burton 1991; Chen und White 2004; Day et al. 1995; Hill et al. 1993; Ingersoll 1995; Ingersoll et al. 1995; Kemble et al. 1994; van Beelen 2003). Dabei handelt es sich zumeist um die klassischen Toxizitätstests Ames-, Leuchtbakterien- und Daphnien-, sowie den Chironomus tentants- und Hyalella azteca-Test.

Für eine Bewertung der Schadwirkung von Sedimenten und Schwebstoffen auf Vertebraten sind labornahe In-vivoVersuche mit intakten Organismen (Fischtest nach DIN 38 412) aufgrund ihrer schlechten Reproduzierbarkeit und ethischer Konflikte problematisch. Daher wurden in den letzten Jahren verstärkt In-vitro-Testverfahren mit Zellkulturen für die Bewertung von partikelgebundenen Schadstoffen entwickelt (vgl. Ahlf et al. 2002b; Engwall et al. 1997a,b, 1998; Hollert et al. 2002a, 2003c; Kosmehl et al. 2007, 2008; Kostanjsek et al. 2005; Otte et al. 2008; Reifferscheid et al. 2008; Wölz et al. 2008). Neben den zellkulturbasierten Methoden wurden in den letzten Jahren auch Testmethoden mit frühen Lebensstadien von Fischen bzw. mit Fischeiern für die Untersuchung von partikelgebundenen Schadstoffen erfolgreich eingesetzt (Braunbeck et al. 2005; Ensenbach 1999; Hallare et al. 2005; Hollert et al. 2003c; Nagel 2002; Strmac et al. 2002).

Im Rahmen der eigenen Studien am Institut für Zoologie in Heidelberg und am Institut für Umweltforschung der RWTH Aachen wurden insbesondere Biotestverfahren eingesetzt, die für eine prospektive Bewertung von Schwebstoffen und Sedimenten geeignet sind. Wichtige Kriterien für solche biologische Testverfahren sind biologische Relevanz, Schnelligkeit, Standardisierbarkeit, mechanistische Interpretierbarkeit sowie vertretbarer personeller und finanzieller Aufwand.

Bei Biotestverfahren können Organismen oder Zellen auf verschiedene Weise gegenüber Sediment- und Schwebstoffproben exponiert werden: Die Untersuchung von nativen Sediment- oder Schwebstoffproben besitzt die größte ökologische Relevanz, da sie die aktuelle Bioverfügbarkeit von Schadstoffen berücksichtigt. Sie kann aber nicht mit allen hier dargestellten Biotests durchgeführt werden (Tabelle 1). Bei vielen In-vitro-Testverfahren ist es daher notwendig, die partikelgebundenen Schadstoffe durch verschiedene Ver- fahrensweisen in die gelöste Phase zu überführen (vgl. Ahlf 1995; Ahlf et al. 2002a,b; Hollert et al. 2003c; Seiler et al. 2008; Ulrich et al. 2002):

- Es kann das native Porenwasser, dem viele aquatische Organismen a priori ausgesetzt sind und das vordergründig den Hauptexpositionspfad von Sedimentschadstoffen darstellt (Burton 1991, Power und Chapman 1992), auf seine biologische Wirksamkeit untersucht werden. Die Art der Sammeltechnik für Porenwasser besitzt einen großen Einfluss auf dessen Toxizität (Bufflap und Allen 1995), die Methoden sind jedoch wenig standardisiert. Zudem können nur begrenzte Mengen effizient gesammelt werden. Das mögliche Schädigungspotenzial der Sedimente und die langfristige Bioverfügbarkeit wird bei der Prüfung von Porenwasser prinzipiell nicht erfasst und de facto meist unterschätzt (Harkey et al. 1994). Porenwasser sollte als Expositionsphase genutzt werden, wenn untersucht werden soll, ob benthosbewohnende Organismen durch die Sedimente geschädigt werden können. Die Handlungsanweisung für den Umgang mit Baggergut im Binnenland (HABAB-WSV; BfG 2000) benutzt die ökotoxikologische Wirkung von Porenwasser im Leuchtbakterien-, Algen- und Daphnientest als wichtiges Kriterium für die Bewertung von Baggergutumlagerungen: „Baggergut, dessen Porenwasser bei einer Verdünnung 1:4 nicht toxisch wirkt, darf umgelagert werden. Bei toxischem Baggergut ist eine Einzelfallentscheidung erforderlich, für die gegebenenfalls weitere Untersuchungen erforderlich werden." Nach Wang (1999) stellen Toxizitätsuntersuchungen von anoxischen Porenwässern, die bereits in Tiefen von wenigen Millimetern vorkommen können, ein großes Problem dar: Durch die aerobe Probenaufarbeitung und die Expositionssituation im Biotest können die Metalle von Sulfiden oxidiert werden (Entstehung von flüchtigem $\mathrm{H}_{2} \mathrm{~S}$ ), so dass die Sulfidtoxizität im Bioassay unterbewertet wird. Andererseits geht mit der Oxidation der Sulfide oft eine Veränderung der Bindungsspezies einher, durch die Schwermetallsulfide und Polysulfid-Komplexe bioverfügbar werden. Die Toxizität dieser Substanzen wird somit im Bioassay oft überbewertet. Die Bedeutung des Porenwassers als wichtigem Expositionspfad für sedimentbewohnende Invertebraten könnte zudem geringer als bisher angenommen sein, da sich diese durch Röhrensysteme ein eigenes Milieu schaffen können, das mehr dem der Wassersäule als dem des Porenwassers gleicht (Wang 1999). Porenwasser für die Biotests kann durch Dialyseverfahren (Bufflap und Allen 1995; Mudroch und MacKnight 1994a,b) oder durch Zentrifugation von nativen Sedimenten bei $4{ }^{\circ} \mathrm{C}$ über $10 \mathrm{~min}$ mit $3000 \times$ g gewonnen werden (Hollert et al. 1999a). Die Untersuchung von Porenwässern mit einer Batterie von Biotests ist aufgrund der geringen Volumina, die sich aus Sedimenten 
gewinnen lassen, mit einem erheblichen Arbeitsaufwand verbunden.

- Die Überprüfung der wässrigen Eluate ${ }^{1}$ von Sedimenten - die durch Schütteln von Sedimenten mit Wasser hergestellt werden - ist relativ gut standardisiert und ahmt oxidierende Umweltverhältnisse nach, wie sie bei einer Remobilisierung von Sedimenten zu erwarten sind. Für wässrige Eluate ist jedoch bekannt, dass sie das tatsächliche bioverfügbare Maß an Schadstoffen unterbewerten (Harkey et al. 1994). Für die Herstellung von wässrigen Eluaten (vgl. Ahlf 1995; Hollert und Braunbeck 1997) werden die Sediment- oder Schwebstoffproben in einer definierten Menge Aqua bidest. (1:2 oder 1:4) suspendiert und für $12 \mathrm{~h}$ bei $4^{\circ} \mathrm{C}$ mit einem Überkopfschüttler mit $20 \mathrm{Upm}$ rotiert. Durch Zentrifugation $(3000 \times \mathrm{g}$ bei $4{ }^{\circ} \mathrm{C}$ ) wird das wässrige Eluat von feinen Partikeln befreit. Die Proben werden nativ oder nach einer Sterilfiltration $(0,2 \mu \mathrm{m})$ in den unten beschriebenen In-vitro-Tests auf ihre ökotoxikologische Wirkung untersucht.

- Organische Sedimentextrakte: Sedimente oder Schwebstoffe können mit organischen Lösungsmitteln wie etwa Aceton extrahiert ${ }^{2}$ werden (Campbell et al. 1992; Ho und Quinn 1993b; Landolt und Kocan 1984; True und Heyward 1990), mittels einer Fraktionierung kann dabei eine Aussage über die Dominanz verschiedener Schadstoffgruppen gemacht werden (Brack 1999; Brack et al. 1999a, 2000; Engwall et al. 1996; Ho und Quinn 1993a,b; Ho et al. 1997; Hollert et al. 1998). Mit organischen Extraktionen kann versucht werden, die langfristige Schädigung von Organismen durch überwiegend fettlösliche Substanzen und eine kurze Exposition gegenüber den potenziell verfügbaren Schadstoffen nachzuahmen. Dieser in der Ökotoxikologie weit verbreitete Ansatz ist in der Literatur nicht unumstritten (vgl. Braunbeck et al. 1995a). Die Extraktion kann z. B. durch einfaches Schütteln mit dem Lösungsmittel Methanol (Kwan und Dukta 1990; Neumann-Hensel et al. 2000a) oder als multiple Extraktion im Soxhlet-Apparat (Hollert und Braunbeck 1997) erfolgen. Grundsätzlich gilt es bei der Extraktion zwischen unterschiedlich stringenten Methoden zu unterscheiden. Die Anwendung eines Extraktionsverfahrens ist daher direkt abhängig vom Untersuchungsziel. Schnell desorbierende und damit leicht bioverfügbare Substanzen können u. a. mithilfe von Cyclodextrinen oder Tenax TA-Beads separiert werden (Cornelissen et al. 1997a,b; Ehlers und Loibner 2006; Puglisi et al. 2003, 2007; Reid et al. 2000; Semple et al. 2003). Für die stärker gebundenen, langsam und sehr langsam desorbierenden Frakti-

\footnotetext{
1 eluieren: Überführung von partikelgebundenen Schadstoffen in die lösliche Phase durch das milde Extrahieren mit Wasser.

2 extrahieren: Überführung von partikelgebundenen Schadstoffen in die lösliche Phase durch mehrmaliges Einwirken von organischen Lösungsmitteln.
}

onen steht eine Reihe als erschöpfend geltende Extraktionsmethoden zur Verfügung. Zu den gängigsten gehören die klassische Soxhlet-Extraktion bzw. ihre moderneren Modifikationen, die automatisierte Pressurized Fluid Extraction (PLE, auch ASE®) sowie verschiedene Varianten des Einsatzes von Mikrowellen (Microwave Assisted Extraction, MAE; Camel 2000, 2001; Dean und Xiong 2000; Luque-Garcia und de Castro 2003, 2004; de Castro und Garcia-Ayuso 1998). Alle konventionellen Herangehensweisen können als aktive Methoden gesehen werden, da sie extern zugeführte Hitze zur Unterstützung des Extraktionsprozesses verwenden. Dies birgt allerdings das Risiko, dass chemische Substanzen degradiert werden oder durch chemische Reaktionen überhaupt erst entstehen (Seiler et al. 2008). Ein neuerer Ansatz versucht diesen Umstand zu verbessern, indem mittels passiver Dialyse schonend aber dennoch erschöpfend extrahiert wird (Seiler et al. 2006).

- Native Sedimente: Verschiedene Sedimenttoxizitätsstudien haben in den letzten Jahren gezeigt, dass die Verwendung von Porenwässern und Eluaten sowie speziell organische Extraktionsverfahren im Verdacht stehen, die tatsächliche Bioverfügbarkeit der Schadstoffe nur unzureichend zu berücksichtigen, so dass sich oftmals Probleme hinsichtlich der Übertragbarkeit der In-vitro-Daten auf das Freiland ergeben. Aus dieser Erkenntnis ergab sich die wissenschaftliche Notwendigkeit, Sedimentkontakttests zu entwickeln. Im kürzlich abgeschlossenen BMBF-Verbundprojekt SeKT (Sedimentkontakttests) wurden eine standardisierte Batterie verschiedener Sedimentkontakttests (Arthrobacter globiformis, Saccharomyces cerevisiae, Caenorhabditis elegans, Lumbriculus variegatus, Danio rerio und Myriophyllum aquaticum) zur Untersuchung von natürlichen und künstlichen Referenzsedimenten sowie zur Ermittlung von Toxizitätsgrenzwerten eingesetzt (Feiler et al. 2005).

Detaillierte Charakterisierungen des Schadstoffpotenzials von Sedimenten lassen sich über die Verwendung verschiedener Expositionsphasen in mehreren Biotests erhalten. Tabelle 1 gibt einen exemplarischen Überblick über wichtige Sediment-Biotestverfahren und die möglichen Expositionspfade. Auch andere Sedimentbiotests haben sich bei internationalen und nationalen Forschungsvorhaben bewährt (Ahlf 1995; Burton 1991, 1995; Duft et al. 2003a,b; Ginn und Pastorok 1992; Ingersoll 1995; Ingersoll et al. 1995; La Point und Fairchild 1992; Long 2000; Neumann-Hensel et al. 2000b; Reynoldson und Day 1993; Traunspurger und Drews 1996; van Beelen und Doelman 1997; Zimmer und Ahlf 1994). Die Biotestverfahren, die im Rahmen verschiedener Forschungsvorhaben an die Untersuchung partikelgebundener Schadstoffe angepasst wurden, sind in Abb. 2 dargestellt. Einige der genannten In-vitro-Biotestverfahren konnten im Rahmen eines Methodenkompendiums des 
Tabelle 1 Exemplarischer Überblick über wichtige Sediment-Biotestverfahren und die möglichen Expositionspfade

\begin{tabular}{|c|c|c|c|c|c|c|c|c|}
\hline & Test & Endpunkt & $\begin{array}{l}\text { Abschnitt/ } \\
\text { Referenz }\end{array}$ & $\begin{array}{c}\text { Natives } \\
\text { Sediment }\end{array}$ & $\begin{array}{l}\text { Poren- } \\
\text { wasser }\end{array}$ & $\begin{array}{c}\text { Wässrige } \\
\text { Eluate }\end{array}$ & $\begin{array}{l}\text { Organische } \\
\text { Extrakte }^{4}\end{array}$ & Stand ${ }^{5}$ \\
\hline \multicolumn{9}{|c|}{ Wirbeltiere (Konsumenten höherer Ordnung): } \\
\hline • & Fischeitest & $\begin{array}{l}\text { Akute Toxizität, } \\
\text { Teratogenität }\end{array}$ & Hollert et al.( 2003) & ja & $\mathrm{ja}^{3}$ & ja & ja & +++ \\
\hline$\bullet$ & Zelltest mit RTG-2 & Akute Toxizität & Keiter et al. (2006) & nein & ja & ja & ja & ++ \\
\hline$\bullet$ & Dot-Blot-Assay & Endokrines Potenzial & Hollert et al. (2005) & $\mathrm{ja}^{1}$ & ja & ja & ja & + \\
\hline$\bullet$ & MVLN -Zell-Assay & Endokrines Potenzial & Khim et al. (1999b) & nein & ja & ja & ja & + \\
\hline$\bullet$ & COMET-Assay, RTG-2 & Gentoxizität & Kosmehl et al. (2007) & $\mathrm{ja}^{1}$ & ja & ja & ja & ++ \\
\hline$\bullet$ & $\begin{array}{l}\text { Histopathologie an } \\
\text { Organen (Fisch) }\end{array}$ & subletale Toxizität & Braunbeck (1998) & ja & $\mathrm{ja}^{3}$ & ja & ja & ++ \\
\hline & $\begin{array}{l}\text { Embryonale } \\
\text { _Hühnerleberkulturen } \\
\text { lose (Konsumenten nieder }\end{array}$ & $\begin{array}{l}\text { EROD-Induktion } \\
\text { rdnung): }\end{array}$ & Hollert et al. (2002a) & nein $^{1}$ & ja & $-\frac{j a}{-}$ & $\begin{array}{c}\text { ja } \\
-----\end{array}$ & ++ \\
\hline $\begin{array}{l}\bullet \\
\bullet \\
\bullet \\
-\end{array}$ & $\begin{array}{l}\text { Nematoden(kontakt)test } \\
\text { Hyalella azteca-Test } \\
\text { Daphnientest } \\
\text { Chironomus tentants-Tes } \\
\text { yonten (Konsumenten nie }\end{array}$ & $\begin{array}{r}\text { Toxizität } \\
\text { Toxizität } \\
\text { Toxizität } \\
\bar{r} \text { Ördnung } \overline{\text { Toxizität }} \text { oder } \bar{D} \text { Destrue }\end{array}$ & $\begin{array}{c}\text { Ahlf (1995) } \\
\text { Ahlf (1995) } \\
\text { Ahlf (1995) } \\
\text { En): - Ahlf }(1995) \text { _ _ }\end{array}$ & $\begin{array}{l}\mathrm{Ja} \\
\mathrm{Ja} \\
\mathrm{Ja} \\
\text { Ja_- - }\end{array}$ & $\begin{array}{c}j a^{3} \\
j a^{3} \\
j a^{3} \\
j a^{3}-\end{array}$ & $\begin{array}{c}\text { ja } \\
\text { ja } \\
\text { ja } \\
- \\
-\end{array}$ & $\begin{array}{c}\text { ja } \\
\text { ja } \\
\text { ja } \\
- \text { ja }\end{array}$ & $\begin{array}{l}+++ \\
+++ \\
+++ \\
++++\end{array}$ \\
\hline$\bullet$ & Bakterien(kontakt)test & Toxizität & $\begin{array}{l}\text { Hollert et al. } \\
(2002 b)\end{array}$ & $\mathrm{Ja}$ & ja & ja & ja & +++ \\
\hline$\bullet$ & Leuchtbakterientest & Toxizität & Ahlf (1995) & $\mathrm{Ja}$ & ja & ja & ja & +++ \\
\hline$\bullet$ & Ames-Test & Mutagenität & $\begin{array}{l}\text { Kosmehl et al. } \\
2004\end{array}$ & $\mathrm{ja}^{2}$ & $\mathrm{ja}^{3}$ & ja & ja & +++ \\
\hline$\bullet$ & Ara-Test & Mutagenität & Vahl et al. (1997) & $\mathrm{ja}^{2}$ & $\mathrm{ja}^{3}$ & ja & ja & ++ \\
\hline & Izenten: & - Gentoxizität & - Vahl et al. (1997) & & & & & \\
\hline$\bullet$ & Algenhemmtest & Toxizität & Ahlf (1995) & nein & $\mathrm{ja}^{3}$ & ja & ja & +++ \\
\hline
\end{tabular}

Grau unterlegt: in dieser Studie eingesetzte Verfahren.

${ }^{1}$ Der COMET-, EROD- und Vitellogenin-Assay kann bei der Untersuchung von Gesamtsediment nicht mit permanenten Zellen, embryonalen Hühnerlebern bzw. Primärhepatocyten, wohl aber an Proben von Organismen aus dem Ökosystem (passives Biomonitoring) angewendet werden.

${ }^{2}$ Der Ames- bzw. ARA-Test kann nur mit autoklaviertem Gesamtsediment durchgeführt werden. Dabei ist von Transformationen chemischer Verbindungen auszugehen, so dass eine Gesamtsedimentuntersuchung mit Hilfe des Ames-, bzw. ARA-Tests nicht empfohlen werden kann.

${ }^{3}$ Die Durchführung des Fischeitests und des Ames-Tests mit Porenwasser erfordert sehr große Mengen der Probe (etwa $100 \mathrm{~mL}$ ).

${ }^{4}$ Extrakte werden für die Toxizitätsuntersuchungen mit Bioassays in der Regel mit Wasser oder einem Nährmedium verdünnt, um eine Toxizität des organischen Lösungsmittels oder Lösungsvermittlers auszuschließen

${ }^{5}$ Entwicklungsstand: + erste Originalarbeiten über Untersuchungen an Sedimenten und Schwebstoffen, ++ mehrere Originalarbeiten oder Ringtests im Zuge einer DIN-Validierung, +++ gültige DIN-, ISO-, EPA- oder ASTM-Vorschriften

Deutschen Verbandes für Wasser- und Kulturbau (DVWK) einem breiten Publikum vorgestellt werden (Brack 1999; Dürr et al. 1999; Ensenbach 1999; Gratzer und Ahlf 1999b; Hollert et al. 1999b,g; Krebs 1999; Rönnpagel et al. 1999; Schnurstein et al. 1999). Bei der Auswahl der Biotests sollten sowohl verschiedene Hierarchie-Ebenen der Organis- men (vgl. auch Abb. 1) als auch unterschiedliche Expositionspfade (s. Tabelle 1 und Abb. 2) berücksichtigt werden.

Durch die alleinige Verwendung eines Biotestverfahrens kann das Schädigungspotenzial von Sedimenten und Schwebstoffen allerdings nicht ausreichend beschrieben werden (Zimmer und Ahlf 1994). Die einzelnen Verfahren

\section{Expositionpfad}

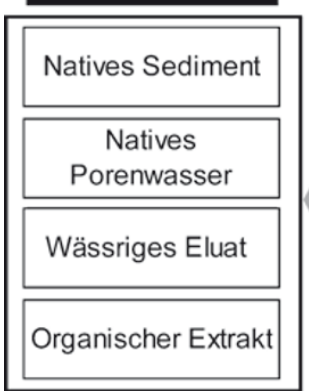

Testorganismus bzw. Testsystem

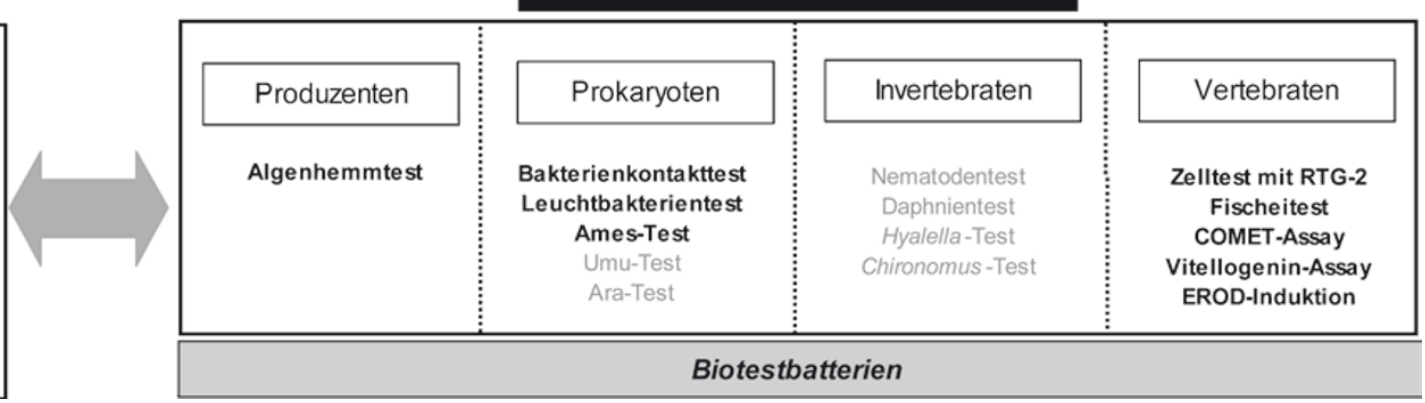

Abb. 2 Biotestverfahren, die im Rahmen verschiedener Forschungsvorhaben an die Untersuchung partikelgebundener Schadstoffe angepasst wurden 
lassen sich in Biotestbatterien kombinieren (Ahlf 1995; Fretwurst et al. 1997; Henschel et al. 2001; Hollert et al. 1999c,e; 2002a,b; Keiter et al. 2006, 2008; Kosmehl et al. 2007; Zimmer und Ahlf 1994). Durch die kombinierte Verwendung lässt sich eine Vielzahl von Informationen über die Sedimenttoxizität erhalten: Von der Schädigung bestimmter Organismen kann nur sehr bedingt auf die Wirkung auf andere Lebewesen geschlossen werden. Obgleich in den meisten Fällen die sedimentinduzierte Schädigung bei verschiedenen Organismen gut korreliert, können bei Dominanz verschiedener Schadstoffgruppen Bakterien, Algen, Invertebraten und Wirbeltiere sehr unterschiedlich reagieren. Daher kann durch die alleinige Verwendung eines Biotests der Zustand von Sedimenten und Schwebstoffen nicht ausreichend bewertet werden. Für das Testdesign sind daher Biotestbatterien anzustreben, die jeweils mindestens einen Vertreter aus den trophischen Ebenen Produzenten, Konsumenten, Konsumenten höherer Ordnung und Destruenten nutzen (Ahlf 1995; Zimmer und Ahlf 1994).

Partikelassoziierte Schadstoffe können unterschiedliche Arten der Schädigung verursachen: Neben einer akuten toxischen Wirkung, die in der Regel mit dem Sterben der Organismen oder Zellen einhergeht, können auch vielfältige subletale Wirkungen auftreten, die für das Ökosystem sehr wohl relevant sein können. Sedimente können prinzipiell auch erbgutverändernd wirken (Mutagenität, Gentoxizität; Chen undWhite 2004), die natürliche Entwicklung von Eiern und Embryonen stören (Teratogenität; Engwall et al. 1994; Ensenbach 1998; Hollert et al. 2003c; Strmac 1999), in den Hormonhaushalt der Tiere eingreifen (endokrine Wirkung; Legler 2001, Duft et al. 2003a,b) oder pathologische Veränderungen in Tieren und Pflanzen (Otto et al. 1994; Strmac und Braunbeck 2000) verursachen. Für umfassende Charakterisierungen des Sedimentzustandes sollten daher zusätzlich zu den (zumeist unspezifischen) akuten Biotests solche mit exakt definierten Endpunkten eingesetzt werden (Chapman und Hollert 2006; Hollert et al.1999a,d,f, 2002b, 2007a; Keiter et al. 2008).

\section{Stufenverfahren}

Insbesondere in angelsächsischen Ländern werden häufig gestufte Beurteilungskonzepte verwendet, um die Qualität von Sedimenten zu bewerten. In einem Positionspapier des Fachausschusses „Gewässersedimente“ der Fachgruppe Wasserchemie in der GDCh (Henschel et al. 2001; Calmano 1996) wurde ein solches gestuftes Bewertungskonzept vorgestellt, das sich weitgehend an Reynoldson und Day (1993) orientiert. Auf jeder Stufe wird entschieden, ob ein Sediment nutzungsbezogen unbedenklich ist oder ob weitere Untersuchungen erforderlich sind. Dabei können Biotestverfahren generell als Screeningmethoden verwendet werden (Calma- no 1996). Auch andere Autoren haben kombinierte chemische und bioanalytische Stufenverfahren vorgeschlagen, die akute und Mechanismus-spezifische Testverfahren kombinieren (z. B. Ahlf et al. 2002a,b; Hollert 2001).

Ein Stufenverfahren braucht nicht weiter vorangetrieben werden, wenn (1) die nutzungsbezogenen Zielvorgaben (z.B. Sicherung der Trinkwasserqualität, Schutz der Lebensgemeinschaften im und auf dem Sediment) erreicht sind oder (2) das ökotoxikologische Gefahrenpotenzial hinreichend charakterisiert ist. Eine Schädigung in nur einem Biotest kann ausreichen, um die Zielvorgaben für Sedimente zu verfehlen (Ahlf 1995). Stufenverfahren sind, da sie den Kostenfaktor betonen und ein übersichtliches Schema bieten, häufig als Managementstrategie für eine Sedimentsanierung oder zur Entscheidungsfindung bei der Umlagerung von Baggergut angeboten worden. Zudem sollte bei Stufenverfahren das Augenmerk auf die Expositionswege gerichtet werden, um allgemeingültige Mechanismen der Wirkung sedimentassoziierter Umweltchemikalien aufzuklären (Calmano 1996).

Bisher existieren in der Bundesrepublik noch keine umfassend validierten Stufenverfahren für die Bewertung von Sedimenten und Schwebstoffen. Einen Überblick über mögliche Stufenverfahren und entsprechende Anwendungen geben Ahlf (1995), Ahlf et al. (2002a,b), Henschel et al. (1997), Hollert (2001), Hollert et al. (2002a,b), van Beelen (2003) sowie Zimmer und Ahlf (1994).

\section{Integrierte Ansätze}

\subsection{Integrierte Sedimentbewertung und Weight-of-evidence Studien}

Um Sedimente unter Sicherstellung der ökologischen Relevanz zu untersuchen und zu bewerten, können verschiedene Ansätze zur integrierten Sedimentbewertung genutzt werden (Abb. 3, Literaturübersichten bei Ahlf 1995; Chapman et al. 1992; Zimmer und Ahlf 1994). „Integrierende Beurteilungen" des Systemzustandes erhält man nach Chapman et al. (1992) durch die Kombination verschiedener Messungen der Umweltqualität. Diese bestehen mindestens aus drei der folgenden fünf Komponenten (Ahlf 1995): (1) chemische Sedimentanalysen, (2) Sedimenttoxizitätstests, (3) Geweberückstandsanalysen, (4) pathologische Untersuchungen und (5) biozönotische Untersuchungen. Obwohl jede einzelne dieser fünf Komponenten wichtige Informationen zum Sedimentzustand bietet, gelangt keine von ihnen zu erschöpfenden Aussagen: Mittels chemischer Analytik kann die Anwesenheit und Konzentration von Schadstoffen im Sediment erfasst werden, sie erlaubt aber keine Aussage über die Bioverfügbarkeit und Wirkung der Substanzen. Sedimenttoxizitätstests im Labor geben zwar Aufschluss über toxische 
Abb. 3 Integrierte Sedimentbewertung

\section{Sedimenttriade nach Chapman et al.}

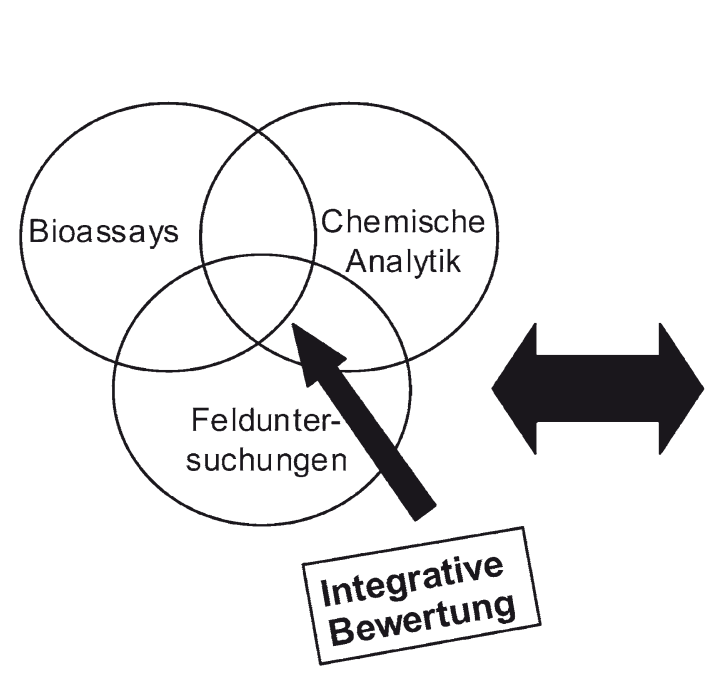

Bioassay-dirigierte Fraktionierung

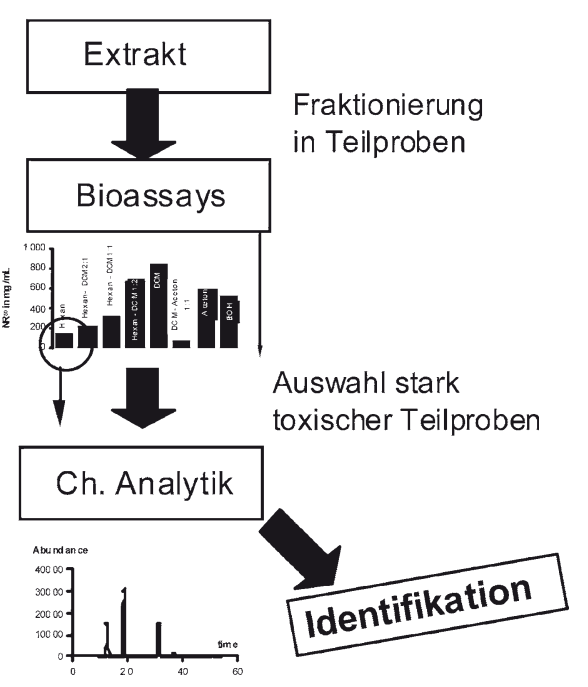

Wirkungen auf die getesteten Organismen und Testsysteme, doch ist die Extrapolation der Daten auf Organismen im Freiland problematisch (Zimmer und Ahlf 1994).

Soll beispielsweise geklärt werden, ob ein bestimmtes Sediment kontaminiert und toxisch ist und ob Lebensgemeinschaften im Sediment Schadeffekte zeigen, so genügt ein vereinfachter, kostengünstigerer Drei-KomponentenAnsatz der integrierten Bewertung (Ahlf 1995). Nach Chapman et al. (1992) sollte in diesem Falle eine Sedimentbewertungstriade aus den Komponenten Sedimentchemie, Sedimenttoxizität in biologischen Tests und Messung von Feldeffekten der benthischen Lebensgemeinschaft (z.B. Pathologie oder Struktur der Biozönose) eingesetzt werden. Integrierte Sedimentbewertungen wurden insbesondere im angelsächsischen Raum (vgl. Carr et al. 1996; Chapman 2000; Power und Chapman 1992), in der Tschechischen Republik (Machala et al. 1998; Staffová et al. 1998), am Golf von Cadíz (DelValls et al. 1998) sowie im Bereich der Nordsee (Karbe et al. 1992; 1994) und an der Elbe (Karbe et al. 1992, 1994) durchgeführt.

An zwölf Fließgewässerstandorten im Einzugsgebiet des Neckars wurde eine Sedimenttriade durchgeführt (Hollert et al. 2002a,b, 2003c, 2005). Es konnten mit Hilfe der Invitro-Bioassays äußerst komplexe Belastungsmuster aus toxischen, teratogenen, gentoxischen, mutagenen, Dioxinähnlichen und endokrinen Effekten nachgewiesen werden. Es konnte mit den Untersuchungen zugleich gezeigt werden, dass eine Bewertung der Fließgewässer mit Bioassays zur akuten Toxizität das Schädigungspotenzial drastisch unterbewerten würde, so dass eine Untersuchungsstrategie für Sedimente unbedingt spezifische Endpunkte beinhalten sollte (Hollert et al. 2002b). Die chemisch-analytischen Unter- suchungen ergaben insgesamt eine gute Korrelation mit den Befunden aus den Bioassays. Eine Berechnung des Anteils der chemisch analysierten Substanzen an der gesamten biologischen Wirksamkeit mit Hilfe von Toxicity-EquivalencyFaktoren zeigte sowohl bei der Dioxin-ähnlichen als auch bei der endokrinen Wirkung, dass selbst eine umfangreiche chemische Analytik die biologische Wirksamkeit nicht abzuschätzen erlaubt (Hollert et al. 2002a, 2005): Während mit Hilfe des TEF-Konzeptes bei den weniger kontaminierten Proben ein Großteil der Dioxin-ähnlichen Wirksamkeit mit den Konzentrationen an PAHs, PCBs und PCDDs/Fs erklärt werden konnte, identifizierte die chemische Analyse nur $0,5-0,7 \%$ des biologisch nachgewiesenen Dioxin-ähnlichen Potenzials der hoch kontaminierten Proben. Mit Hilfe von Makrozoobenthosaufnahmen und der Verwendung zahlreicher Indices konnte die ökologische Relevanz der biologischen und chemischen Analysen verifiziert werden (Hollert et al. 2002a). Es zeigte sich, dass der Saprobienindex die Degradation der Biozönose drastisch unterbewerten kann, wogegen in Kombination mit dem ökotoxikologischen Index eine sehr differenzierte Bewertung des Zustandes in situ möglich war. Insgesamt erwies sich das Konzept der Sedimentbewertungstriade als geeignete Strategie für eine umfassende Beschreibung des ökotoxikologischen Schädigungspotenzials der untersuchten Fließgewässer. Eine weitere Weight-of-evidence-Studie an einer Flachwasserzone am unteren Neckar, die durch stark gestörte Zusammensetzung der Fischgemeinschaften und entsprechende adverse Effekte aufgefallen ist, stellen Braunbeck et al. (2009) in einem eigenen Artikel in diesem Sonderheft vor.

Intensiv hat das Zoologische Institut in Heidelberg in den letzten fünf Jahren eine Weight-of-Evidence-Studie an 
der Oberen Donau beschäftigt. Die Fischbestände in der Donau zwischen Sigmaringen und Ulm sind seit Ende der 1980er-Jahre stark rückläufig (Wurm 2001). Trotz intensiver bestandsstützender Maßnahmen und einer verbesserten Wasserqualität entlang der Donau seit den 1970er-Jahren konnte dieser Entwicklung nicht entgegengewirkt werden. Ergebnisse einer Pilotstudie (Keiter et al. 2006) ergaben, dass Abschnitte der oberen Donau ein hohes ökotoxikologisches Belastungspotenzial aufwiesen. Insbesondere den Sedimenten kam in dieser Studie als Senke und auch mögliche Quelle für die Schadstoffe eine große Bedeutung zu. In einer nachfolgenden Studie, die auch in diesem Sonderheft in einem Artikel von Keiter et al. (2009) vorgestellt wird, sollte eine umfassende integrierte Bewertung im Sinne eines Triadeansatzes durchgeführt werden (Grund et al. 2009a,b; Keiter et al. 2008; Otte et al. 2008; Seitz et al. 2008). In den Sediment-Untersuchungen wurden verschiedene Biotestverfahren angewendet (Cytotoxizitätstest, Mikrokerntest, Comet-Assay und EROD-Assay mit der Zelllinie RTL-W1, der neu entwickelte Sedimentkontakttest auf Embryotoxizität und Gentoxizität mit Fischeiern von Danio rerio, Bakterienkontakttest mit Arthrobacter globiformis, Ames-Test, Yeast Estrogen Screen-Assay und DR-CALUX-Assay). Insbesondere um die Biotestbefunde mit der Situation im Freiland zu korrelieren, wurden Störungen in der Makrozoobenthosgemeinschaft und des Gesundheitszustandes einer ausgewählten Fischart untersucht. Neben histopathologischen Untersuchungen zur ultrastrukturellen Organisation der Leber mittels Elektronenmikroskopie an der Barbe (Barbus barbus) wurde der Mikronukleustest als definitiver Mutagenitätsendpunkt an Erythrocyten und Leberproben von Barben aus dem Freiland und entsprechenden Kontrolltieren als Insitu-Parameter untersucht. Weiterhin wurden limnochemische Summenparameter sowie anorganische und organische Schadstoffe in den Sedimentproben gemessen.

Kürzlich wurde von Chapman und Hollert (2006) vorgestellt, dass das Konzept der Sedimentbewertungstriade und allgemeiner Weight-of-Evidence-Studien um zusätzliche Beweislinien (Lines-of-Evidence) erweitert werden kann. So ist etwa der gezielte Einsatz von histologischen und gentoxikologischen In-situ-Methoden an Fischen aus dem Feld als eine zusätzliche Beweislinie, die die Relevanz von labornahen Untersuchungen auf die Situation im Freiland bewerten können, sinnvoll.

\section{Effekt-dirigierte Analysen}

Durch die Verwendung von Biotests kann das Schädigungspotenzial der partikelgebundenen Schadstoffe summarisch erfasst werden, die problematischen Substanzen können jedoch nicht identifiziert werden. Eine Möglichkeit, nähere Auskunft über die Substanzgruppen zu erhalten, die für die toxischen Wirkungen verantwortlich sind, stellt die Effektdirigierte Analyse (EDA, engl.; ähnlich auch TIE = Toxicity Identification Evaluation) dar (Ankley und Schubauer-Berigan 1995; Brack 2003; Brack et al. 1998, 2005b; Engwall et al. 1996; Ho et al. 1997; Ho und Quinn 1993a,b; Hollert et al. 1998). Bei der Effekt-dirigierten Analyse kann durch die Kombination aus chemischen Fraktionierungstechniken, Biotests und nachgeschalteten chemisch-analytischen Untersuchungen der jeweils problematischen Fraktionen eine nähere Charakterisierung der toxischen Stoffe erzielt werden (s. Abb. 3). Bioassay-dirigierte Fraktionierungen können insbesondere in gestuften Bewertungsverfahren zur Identifizierung problematischer Substanzklassen bzw. Schadstoffe führen. Diese Methodik wird vor allem an bekannten hochbelasteten Standorten eingesetzt, da an diesen die Effekt-verursachenden Schadstoffe vorrangig zu identifizieren sind. Sie kann aber auch eingesetzt werden um wichtige Informationen über Umweltproben unbekannter Zusammensetzung, z.B. über die Auswirkungen von Schwebstoffen nach Sedimenterosion im Hochwasserverlauf, zu erlangen.

Chromatographische Auftrennungen von Extrakten wurden insbesondere für gentoxische Biotests mehrfach angewendet; Grifoll et al. (1990) verwendeten dazu Aluminiumoxid-Säulen, West et al. (1986), Brack et al. (2005a, 2007) und Lubcke-von Varel et al. (2008) Aluminiumoxid-Säulen in Verbindung mit Normalphasen/Umkehrphasen-HPLC, Jarvis et al. (1996) eine Silicagel-Fraktionierung, Braunbeck et al. (1997), Erdinger et al. (1997), Hollert und Braunbeck (1997), Hollert et al. (1998) und Samolloff et al. (1983) eine Florisil $^{\circledR}$-Fraktionierung, Fernandéz et al. (1992) eine Kombination aus Gelpermeationschromatographie, Normalphasen-HPLC und Umkehrphasen-HPLC sowie Maruoka et al. (1986) eine Dünnschichtchromatographie (TLC) mit anschließender HPLC-Auftrennung. Mutagene Wirkung wurde z.B. mit dem Ames- und dem umu-Test nachgewiesen (Brack et al. 2005b). Zum Nachweis der Dioxin-ähnlichen Wirksamkeit wurden Extrakte von Umweltproben mehrfach mit Säulenchromatographie beziehungsweise HPLC aufgetrennt und in permanenten Zellkulturen mit den Zelllinien RTL-W1 (Brack et al. 1999b, 2000, 2005b; Wölz et al. 2008) und H4IIE-luc (Hilscherova et al. 2000; Khim et al. 1999a,b) oder in embryonaler Hühnerleberkultur (Brunström et al. 1992; Engwall et al. 1994, 1996, 1997a,b, 1998; Norrgren et al. 1998) untersucht. Zur Identifizierung akut toxischer Substanzen haben Ho und Quinn (1993b) eine Flüssig/Flüssig-Extraktion und Reemtsma et al. (1999) eine HPLC-Fraktionierung mit dem Endpunkt Microtox-Assay durchgeführt, Galassi und Benfenati (2000) untersuchten die Toxizität von HPLC-Extrakten mit Daphnia magna, Cytotoxizitätstests mit RTG-2-Zellen wurden mit HPLC-Extrakten von Abwasserproben (Castano et al. 1994) und Fraktionen einer Florisil ${ }^{\mathbb{Q}}$-Trennung von Schwebstoffextrakten 
(Braunbeck et al. 1997; Hollert und Braunbeck 1997) untersucht. Brack et al. (1998, 1999b) kombinierten eine Alumina- und HPLC-Fraktionierung von Sedimentextrakten mit einer Biotestbatterie aus Vibrio fischeri, Daphnia magna, dem Algenhemmtest mit Scenedesmus vacuolatus und dem Cytotoxizitätstest mit der Zelllinie RTG-2.

Am Beispiel eines hoch belasteten Baches im Einzugsgebiet des Neckars wurden z. B. komplexe Effekt-dirigierte Analysen (Alumina-Säulenchromatographie, Normalphasen- und Umkehrphasen-HPLC) durchgeführt, um die Substanzen zu identifizieren, die für das hohe mutagene und Dioxin-ähnliche Schädigungspotenzial der Sedimentproben verantwortlich waren. Es konnte z. B. gezeigt werden, dass neben Benzo $[a]$ pyren und Benzo $[a]$ fluoranthen auch Perylen einen großen Anteil des gentoxischen Potenzials erklärte (Brack et al. 2005b). Neben den lipophileren Schadstoffen wurde ein Schwerpunkt auf die Untersuchung der polareren Inhaltsstoffe gelegt. Bei einer Fraktionierung und Massenbilanzierung von Hochwasserschwebstoffen des Neckars konnte beispielsweise nach einer Säure-Base-Trennung gezeigt werden, dass persistente organische Schadstoffe nur einen kleinen Teil des Dioxin-ähnlichen Potenzials erklärten (Wölz et al. 2008). Mit nachgeschalteter Effekt-dirigierter Analyse mittels einer kürzlich entwickelten HPLC-Methode konnte gezeigt werden, dass insbesondere die prioritären und die nicht-prioritären PAHs einen großen Anteil am gesamten Dioxin-ähnlichen Potenzial besitzen.

\section{Sedimentmobilität und Hochwasserfolgenbewertung}

Sedimente in Flüssen haben ihren Ursprung hauptsächlich in der Erosion von terrestrischen Oberflächen und des Flusskanals selbst. Ihre Verlagerung im Fluss erfolgt in Richtung Küsten, so dass sie letztlich in den Flussdeltas und den Ozeanen abgelagert werden. Innerhalb der Flusssysteme können Sedimente zeitweilig stabil zwischengelagert vorliegen. Zusätzlich können sie z. B. in Auen und Überflutungsgebieten eingetragen werden. In diesem Kontext ist $\mathrm{zu}$ beachten, dass Sedimente, bedingt durch ihre Zusammensetzung (anorganische und organische Bestandteile), eine Vielzahl von Bindungsstellen für Schadstoffe besitzen. Folglich können Sedimente Senken für Schadstoffe darstellen und diese der Wassersäule entziehen. Andererseits können sie im Fall von Hochwassern und bei Verklappungen auch Schadstoffquellen darstellen (Ahlf et al. 2002b; Hollert et al. 2000, 2003a; Oetken et al. 2005). Fragen der Sedimentstabilitätsbewertung und die damit verbundenen Unsicherheiten werden bei der weiteren Umsetzung der Wasserrahmenrichtlinie eine wichtige Rolle spielen (Hollert et al. 2007a,b). Die hohe Relevanz der Sedimentremobilisierung und die dadurch erhöhte Bioverfügbarkeit von Schadstoffen werden in Folge der zu erwartenden Auswirkungen des Klimawandels deutlich.
Allgemein wird weltweit mit einem verstärkten globalen Wasserkreislauf gerechnet, der auch zu einer Zunahme von Hochwasserrisiken führt (Hulme et al. 2002; Wilby et al. 2006). Hochwasser werden in Frequenz und Intensität in vielen Regionen der Welt zunehmen (Ikeda et al. 2005; Kay et al. 2006). In Mitteleuropa wird beispielsweise mit einer Zunahme von extremen Wetterereignissen und Starkregen gerechnet, die zu einem gehäuften und verstärkten Auftreten von Hochwasserereignissen führen. Dadurch werden Jahrhunderthochwasser wie das an der Elbe 2002 und ihre Auswirkungen zunehmend häufiger. Um der resultierenden Bedrohung zu entgehen, werden derzeit in vielen Ländern bereits zusätzlich Rückhalteräume ausgewiesen, wie beispielsweise im „Integrierten Rhein-Programm (IRP)“ entlang des Rheins in Baden-Württemberg (Disse und Engel 2001).

Allerdings ist es neben baulichen Maßnahmen zur Minimierung der Schäden durch die Hochwasserwelle selbst wichtig, auch die mittransportierte Schadstofffracht zu berücksichtigen. Während in besiedelten und industriell genutzten Gebieten vor allem ursprünglich an Land gelagerte Gefahrenstoffe verdriftet werden, sind insbesondere in industriefernen Gebieten die im Flusssystem remobilisierten Schadstoffdepots wichtige Kontaminationsquellen. Ein umfassendes und integratives Hochwassermanagement muss auch die Auswirkungen solcher Schadstofffrachten berücksichtigen.

Das Verbundprojekt SEDYMO („,Feinsedimentdynamik und Schadstoffmobilität in Fließgewässern“; Westrich und Foerstner 2007) wurde vom Bundesministerium für Bildung und Forschung (BMBF) in dem oben genannten Kontext von Mai 2002 bis Juli 2006 gefördert. Es umfasste 13 Forschungsprojekte, und sein interdisziplinärer Ansatz konzentrierte sich auf die Umlagerung von kontaminierten Sedimenten und Freisetzung von Nährstoffen und Schadstoffen in die Wassersäule als Folge hydrodynamischer Prozesse in Flüssen und Ästuaren. Es wurde deutlich gemacht, dass bei der Umsetzung der europäischen Wasserrahmenrichtlinie (und anderer flusseinzugsgebiets-übergreifender Bewirtschaftungskonzepte) die Berücksichtigung des Faktors ,Erosionsstabilität von Sedimenten“ unverzichtbar ist. Ein wichtiger Beitrag war die Entwicklung von experimentellen Techniken und Modellen für die Übertragung von Laborbefunden auf die In-situ-Bedingungen. In einem kürzlich erschienenen Buch werden u.a. die Unsicherheiten von chemischen, hydraulischen und biologischen Sedimentdaten behandelt (Ahlf und Heise 2007; Westrich et al. 2007) und auch die Notwendigkeit einer gemeinsamen Betrachtung von Sedimentmobilität und -toxizität aufgezeigt (Hollert et al. 2007a).

Bisher wurden Fragestellungen zu den Auswirkungen von Hochwasserereignissen im Kontext der Sediment-gebundenen Schadstofffrachten noch nicht hinreichend untersucht. 
Um diese Lücken zu schließen, wird derzeit beispielsweise in einem BMBF-Verbundprojekt (RIMAX-HoT) am Standort des geplanten Rückhalteraums Bellenkopf-Rappenwört (bei Karlsruhe) untersucht, welche Auswirkungen (extreme) Hochwasserereignisse auf die Trinkwasserversorgung haben können (Maier et al. 2005). Im Rahmen der Exzellenzinitative wurde an der RWTH Aachen im Rahmen des Pathfinder FLOODSEARCH-Projektes kürzlich begonnen, in einem integrativen hydraulischen und toxikologischen Ansatz die ökologische Relevanz von kurzfristig remobilisierten Sedimenten auf aquatische Systeme zu untersuchen (Wölz et al. 2009). Andere Fragestellungen betreffen die weitere Nutzung von flussnahen landwirtschaftlichen Nutzflächen, z. B. für die Viehhaltung. All diese Aspekte weisen auf die hohe gesellschaftliche Relevanz der Untersuchung und des Monitorings von Sedimentbelastungen in Flüssen im Kontext der Hochwasserfolgenbewertung hin.

\section{Ausblick}

Um die Bedeutung von Sedimenten für flussgebietsbezogene Managementansätze in verschiedenen Regionen Europas zu erörtern, organisierte das Europäische Sedimentnetzwerk „SedNet“ vom 22. bis 23. November 2006 ein Round-Table-Gespräch in den Gebäuden der UNESCO in Venedig. Geladen waren aus den vier Einzugsgebieten Donau, Douro, Elbe und Humber Wissenschaftler, Flussgebietsmanager und Vertreter von Nutzergruppen, deren Tätigkeit direkt oder indirekt von der Sedimentqualität und/oder dem Sedimenthaushalt beeinflusst wird. Sie diskutierten die spezifische Notwendigkeit einer Integration von Sedimenten in die jeweiligen Flussgebietsmanagementpläne (Netzband et al. 2007).

Es stellte sich heraus, dass Sedimente in allen Einzugsgebieten ein Thema waren, und dies entweder in Bezug auf ihre Qualität, auf ihre Quantität oder häufiger in Bezug auf eine Kombination aus beidem.

Trotz der beträchtlichen Fortschritte bei der Umsetzung der WRRL dokumentieren die Bestandsaufnahmen der Bundesländer, dass viele Gewässer den, guten ökologischen und chemischen Zustand' bis 2015 nicht erreichen werden (Übersicht dazu bei Hollert et al. 2007b). Während insgesamt eine umfangreiche Methodik zur Umsetzung der WRRL erarbeitet wurde, sehen Hollert et al. (2007b) insbesondere für die Wasserkörper mit unzureichender chemischer Qualität Nachholbedarf bei der Bestandaufnahme und im Monitoring. Obgleich schon jetzt in vielen Fällen die problematischen ,prioritären' und ,prioritären gefährlichen Schadstoffe' bekannt sind und im Kontext der Bewirtschaftungspläne reduziert oder gar eliminiert werden können, steht in anderen Fällen das entsprechende Wissen bzw. die Methodik noch nicht zur Verfügung. Gründe da- für sind u.a. in der starken ökologischen Ausrichtung der WRRL zu sehen. Obgleich dieser Ansatz zu den Stärken der WRRL zählt, hat er auch dazu geführt, dass etwa die partikelgebundenen Schadstoffe und die, historische Verschmutzung aus Sedimenten' als neue Verschmutzungsursache für Oberflächengewässer lange vernachlässigt wurden (Heise und Förstner 2006). Dies kann auch dazu führen, dass wichtige Nutzungsansprüche, z. B. bei der Schifffahrt und dem dafür erforderlichen Baggergutmanagement oder bei der landwirtschaftlichen Nutzung von Auenböden, bei der Formulierung der Bewirtschaftungsziele nicht ausreichend berücksichtigt werden (Netzband et al. 2007). Die Kombination aus chemischen und ökotoxikologischen Sedimentuntersuchungen unter der Berücksichtigung der Sedimentmobilität bietet große Potenziale hinsichtlich der Identifizierung und Eliminierung von Risiken aus kontaminierten (Alt)sedimenten.

Wie weiterhin an verschiedenen Fallbeispielen in diesem Artikel verdeutlicht wird, besitzt insbesondere (i) das Konzept der Effekt-dirigierten Analysen und (ii) der kombinierte Einsatz von akuten und Mechanismus-spezifischen Biotestverfahren sowie In-situ-Untersuchungen in Weightof-Evidence-Studien ein großes Potenzial für die Kausalanalyse von komplexen Umweltproblemen in aquatischen Systemen und für die Maßnahmenprogramme in den Bewirtschaftungsplänen chemisch belasteter Flüsse.

\section{Literatur}

Ahlf W (1995) Biotests an Sedimenten. In: Steinberg C, Bernhardt H, Klappner H (Hrsg), Handbuch Angewandte Limnologie Teil Aquatische Ökotoxikologie. Ecomed, Landsberg, pp 1-43

Ahlf W, Dahn M, Förstner U, Wild-Metzko S (1991) Biologisches Bewertungskonzept für Sedimente. Vom Wasser 76:215-223

Ahlf W, Heise S (2007) Quality assurance of ecotoxicological sediment analysis. In: Westrich B, Förstner U (Hrsg), Sediment dynamics and pollutant mobility in rivers-Interdisciplinary approach. Springer, Heidelberg, pp 380-391

Ahlf W, Braunbeck T, Heise S, Hollert H (2002a) Sediment and Soil Quality Criteria. In: Burton F, McKelvie I, Förstner U, Guenther A (Hrsg), Environmental Monitoring Handbook. McGrawHill, New York, pp 17.1-18

Ahlf W, Hollert H, Neumann-Hensel H, Ricking M (2002b) A Guidance for the Assessment and Evaluation of Sediment Quality: A German Approach Based on Ecotoxicological and Chemical Measurements. J Soils Sediments 2:37-42

Ankley GT, Schubauer-Berigan MK (1995) Background and overview of current standard toxicity identification evaluation procedures. J Aquat Ecosys Health 4:133-149

BfG (2000) Handlungsanweisungen für den Umgang mit Baggergut im Binnenland (HABAB-WSV), Koblenz

Brack W (1999) Sequentielle Teststrategie zur Identifikation toxischer organischer Substanzen in Porenwässern und Sedimentextrakten. In: DVWK, Kern U, Westrich B (Hrsg), Methoden zur Erkundung, Untersuchung und Bewertung von Sedimentablagerungen und Schwebstoffen in Gewässern. DVWK-Schriften, Band 128. Kommissionsbetrieb Wirtschafts- und Verlagsgesellschaft Gas und Wasser mbH, Bonn, pp 282-289 
Brack W (2003) Effect-directed analysis: a promising tool for the identification of organic toxicants in complex mixtures? Anal Bioanal Chem 377:397-407

Brack W, Altenburger R, Ensenbach U, Nehls S, Segner H, Schüürmann G (1998) Hazard assessment of a contaminated sediment using a biotest battery, 8th Annual Meeting of SETAC-Europe, Bordeaux, pp. Poster 1D/P007

Brack W, Altenburger R, Ensenbach U, Möder M, Segner H, Schüürmann G (1999a) Bioassay-directed Identification of organic toxicants in river sediments in the industrial region of Bitterfeld (Germany) - a contribution to Hazard assessment. Arch. Environ. Cont. Toxicol. 37:164-174

Brack W, Hollert H, Kind T, Segner H, Schüürmann G (1999b) Effectdirected identification of EROD-inducing and mutagenic compounds in sediment extracts. In: SETAC (Hrsg.), 20th Annual Meeting of the Society of Environmental Toxicology and Chemistry, Philadelphia, USA

Brack W, Segner H, Möder M, Schüürmann G (2000) Fixed-effectlevel toxicity equivalents - a suitable parameter for assessing ethoxyresorufin-O-deethylase induction potency in complex environmental samples. Environ Tox Chem 19:2493-2501

Brack W, Bakker J, de Deckere E, Deerenberg C, van Gils J, Hein M, Jurajda P, Kooijman B, Lamoree M, Lek S, Lopez de Alda MJ, Marcomini A, Munoz I, Rattei S, Segner H, Thomas K, von der Ohe PC, Westrich B, de Zwart D, Schmitt-Jansen M (2005a) MODELKEY. Models for assessing and forecasting the impact of environmental key pollutants on freshwater and marine ecosystems and biodiversity. Environ Sci Pollut Res 12:252-256

Brack W, Schirmer K, Erdinger L, Hollert H (2005b) Effect-directed analysis of mutagens and ethoxyresorufin-O-deethylase inducers in aquatic sediments. Environ Toxicol Chem 24:2445-2458

Brack W, Klamer HJ, Lopez de Alda M, Barcelo D (2007) Effect-directed analysis of key toxicants in European river basins a review. Environ Sci Pollut Res 14:30-38

Braunbeck T, Berbner T, Bieberstein U, Erdinger L, Geier V, Hollert H, Leist E, Rahman N, Zipperle J (1995a) Toxikologische und Ökotoxikologische Untersuchung und Bewertung verschiedener Kompartimente in Fließgewässern mit Hilfe eines mehrstufigen Prüfsystems mit Zellkulturen aus Fischen. Veröff PAÖ:345-358

Braunbeck T, unter Mitarbeit von Arnold H, Bauer I, Briese I, Hauck C, Hollert H, Holzschuh J, Islinger M, Müller F, Zahn T (1995b) Zelltests in der Ökotoxikologie-Cytotoxizitätstets mit Zellkulturen aus Fischen als Alternative und Ergänzung zu konventionellen Fischtests. Veröff. PAÖ, 11. Landesanstalt für Umweltschutz des Landes Baden-Württemberg, Karlsruhe, 204 pp

Braunbeck T, Hollert H, Dürr M, Erdinger. L (1997) Biotests in der Ökotoxikologie am Beispiel des Fischzelltests. Veröff. PAÖ 22:241-256

Braunbeck T, Böttcher M, Hollert H, Kosmehl T, Lammer E, Leist E, Rudolf M, Seitz N (2005) Towards an alternative for the acute fish LC50 test in chemical assessment: the zebrafish (Danio rerio) embryo toxicity test - an update. ALTEX 22(2):87-102

Braunbeck T, Hollert H, Brauns A, Keiter S, Schwartz P (2009) Fischpopulationen unter Stress - das Beispiel des Unteren Neckars. Umweltwiss Schadst Forsch 21(2), DOI:10.1007/s12302-0090044-6

Brunström B, Broman D, Dencker L, Näf C, Vejlens E, Zebühr Y (1992) Extracts from settling particulate matter collected in the Stockholm archipelago waters: Embryolethality, immunotoxicity, and EROD-inducing potency of fractions containing aliphatics/ monoaromatics, diaromatics, or polyaromatics. Environ Toxicol Chem 11:1441-1449

Bufflap SE, Allen HE (1995) Comparison of pore water sampling techniques for trace metals. Wat Res 29:2051-2054

Burton GA (1991) Assessing the toxicity of freshwater sediments. Environ Toxicol Chem 10:1585-1627
Burton GA (1995) Sediment toxicity testing issues and methods. In: Hoffman DJ, Rattner BA, Burton GA, Cairns J (Hrsg), Handbook of Ecotoxicology. Lewis-Publishers, Boca Raton, pp 70-103

Calmano (1996) Notwendigkeit einer ökotoxikologischen Beurteilung von Sedimenten - Positionspapier des Fachausschusses „Gewässersedimente" der Fachgruppe Wasserchemie der GDCh. Acta hydrochim hydrobiol 24:101-103

Camel V (2000) Microwave-assisted solvent extraction of environmental samples. TrAC-Trends in Analytical Chemistry 19:229-248

Camel V (2001) Recent extraction techniques for solid matrices-Supercritical fluid extraction, pressurized fluid extraction and microwave-assisted extraction: Their potential and pitfalls. Analyst 126:1182-1193

Campbell M, Bitton G, Koopman B, Delfino JJ (1992) Preliminary comparision of sediment extraction procedures and exchange solvents for hydrophobic compounds based on inhibition of bioluminescence. Environ Toxicol Water Quality 7:329-338

Carr RS, Long ER, Windom HL, Chapman DC, Thursby G, Sloane GM, Wolfe DA (1996) Sediment quality assessment studies of Tampa Bay, Florida. Environ Toxicol Chem. 15:1218-1231

Castano A, Vega M, Balzquez T, Tarazona JV (1994) Biological alternatives to chemical identification for the ecotoxicological assessment of industrial effluents: The RTG-2 in vitro cytotoxicity test. Environ Toxicol Chem 13:1607-1611

Chapman PM (2000) The Sediment Quality Triad: then, now and tomorrow. Envrion Sci Pollut Res 13:351-356

Chapman PM, Hollert H (2006) Should the sediment quality triad become a tetrad, a pentad, or possibly even a hexad? J Soils Sediments 6:4-8

Chapman PM, Power EA, Burton GA (1992) Integrative assessments in aquatic ecosystems. In: Burton GA (ed), Sediment toxicity assessment. Lewis, Boca Raton, pp. 313-340

Chen GS, White PA (2004) The mutagenic hazards of aquatic sediments: a review. Mutation Research-Reviews in Mutation Research 567:151-225

Cornelissen G, vanNoort PCM, Govers HAJ (1997a) Desorption kinetics of chlorobenzenes, polycyclic aromatic hydrocarbons, and polychlorinated biphenyls: Sediment extraction with $\operatorname{Tenax}(\mathrm{R})$ and effects of contact time and solute hydrophobicity. Environ Toxicol Chem 16:1351-1357

Cornelissen G, VanNoort PCM, Parsons JR, Govers HAJ (1997b) Temperature dependence of slow adsorption and desorption kinetics of organic compounds in sediments. Environ Sci Technol $31: 454-460$

Day K, Dutka B, Kwan K, Batista N, Reynoldson T, Metcalfe-Smith J (1995) Correlations between solid-phase microbial screening assays, whole-sediment toxicity tests mith macroinvertebrates and in situ benthic community structure. J Great Lakes Res 21: 192-206

Dean JR, Xiong G (2000) Extraction of organic pollutants from environmental matrices: selection of extraction technique. Trends Analyt Chem 19:553-564

de Castro MDL, Garcia-Ayuso LE (1998) Soxhlet extraction of solid materials: An outdated technique with a promising innovative future. Anal Chim Acta 369:1-10

DelValls TA, Forja JM, Gómez-Parra A (1998) Integrative assessment of sediment quality in two littoral ecosystems from the gulf of Cádiz, Spain. Environ Tox Chem 17:1073-1084

Disse M, Engel H (2001) Flood Events in the Rhine Basin: Genesis, Influences and Mitigation. Natural Hazards 23:271-290

Duft M, Schulte-Oehlmann U, Weltje L, Tillmann M, Oehlmann J (2003a) Stimulated embryo production as a parameter of estrogenic exposure via sediments in the freshwater mudsnail Potamopyrgus antipodarum. Aquat Toxicol 64:437-49

Duft M, Schulte-Oehlmann U, Tillmann M, Markert B, Oehlmann J (2003b) Toxicity of triphenyltin and tributyltin to the freshwater 
mudsnail Potamopyrgus antipodarum in a new sediment biotest. Environ Toxicol Chem 22:145-52

Dürr M, Hollert H, Erdinger L (1999) Bakterien-Kurzzeittest zur Bestimmung des genotoxischen Potentials von Wasser, Schwebstoffen und Sedimenten. In: DVWK, Kern U, Westrich B (Hrsg), Methoden zur Erkundung, Untersuchung und Bewertung von Sedimentablagerungen und Schwebstoffen in Gewässern. DVWK-Schriften, Band 128. Kommissionsbetrieb Wirtschafts- und Verlagsgesellschaft Gas und Wasser mbH, Bonn, pp 263-267

EC (2006) Draft für eine Richtlinie des Europäischen Parlamentes und des Rates über Umweltqualitätsnormen im Bereich der Wasserpolitik und zur Änderung der Richtlinie 2000/60/EG. http://ec.europa.eu/environment/water/water-dangersub/pdf/ com_2006_397_en.pdf

Ehlers GAC, Loibner AP (2006) Linking organic pollutant (bio)availability with geosorbent properties and biomimetic methodology: A review of geosorbent characterisation. and (bio)availability prediction. Environ Pollution 141:494-512

Engwall M, Brunström B, Brewer A, Norrgren L (1994) Cytochrome p450IA induction by coplanar PCB, a PAH mixture, and PCBcontaminated sediment extracts following microinjection of rainbow trout sac-fry. Aquatic Toxicol 30:311-324

Engwall M, Broman D, Ishaq R, Näf C, Zebühr Y, Brunström B (1996) Toxic potencies of lipophilic extracts from sediments and settling particulate matter (SPM) collected in a PCB contaminated river system. Environ Tox Chem 15:213-222

Engwall M, Broman D, Dencker L, Naf C, Zebuhr Y, Brunstrom B (1997a) Toxic potencies of extracts of sediment and settling particulate matter collected in the recipient of a bleached pulp mill effluent before and after abandoning chlorine bleaching. Environ Tox Chem. 16:1187-1194

Engwall M, Broman D, Naf C, Zebuhr Y, Brunstrom B (1997b) Dioxin-like compounds in HPLC-fractionated extracts of marine samples from the east and west coast of Sweden: Bioassay- and instrumentally-derived TCDD equivalents. Mar Pollution Bull. 34:1032-1040

Engwall M, Naf C, Broman D, Brunstrom B (1998) Biological and chemical determination of contaminant levels in settling particulate matter and sediments - A Swedish river system before, during, and after dredging of PCB-contaminated lake sediments. Ambio. 27:403-410

Ensenbach U (1998) Embryonic development of fish-A model to assess the toxicity of sediments to vertebrates. Fresenius Environmental Bulletin. 7:531-538

Ensenbach U (1999) Einfluß von Fremdstoffen auf die Embryonalentwicklung des Zebrabärblings (Danio rerio). In: DVWK, Kern U, Westrich B (Hrsg), Methoden zur Erkundung, Untersuchung und Bewertung von Sedimentablagerungen und Schwebstoffen in Gewässern. DVWK-Schriften, Band 128. Kommissionsbetrieb Wirtschafts- und Verlagsgesellschaft Gas und Wasser mbH, Bonn, pp. 269-273

Erdinger L, Höpker K-A, Dörr I, Fried M, Dürr M (1997) Genotoxische organische Verbindungen in der Außenluft. Identität, Transformation und ökotoxikologische Bedeutung. Veröff. PAÖ., 25, Karlsruhe, $215 \mathrm{pp}$

Feiler U, Ahlf W, Hoess S, Hollert H, Neumann-Hensel H, Meller M, Weber J, Heininger P (2005) The SeKT joint research project: definition of reference conditions, control sediments and toxicity thresholds for limnic sediment contact tests. Environ Sci Pollut Res 12:257-258

Fernandéz R, Grifoll PM, Sonas AM, Bayona JM, Albaiges J (1992) Bioassay-directed chemical analysis of genotoxic components in coastal sediments. Environ Sci Technol 26:817-829

Förstner U (2002) Sediments and the European Water Framework Directive. J Soils Sediments 2:54
Förstner U, Müller G (1974) Schwermetalle in Flüssen und Seen. Spinger-Verlag, Heidelberg, 225 pp

Förstner U, Calmano W, Ahlf W, Kersten M (1989) Ansätze zur Beurteilung der Sedimentqualität von Gewässern. Vom Wasser 73:25-42

Fretwurst S, Gratzer H, Stachel B, Ahlf W (1997) Erprobung einer Biotestkombination an einem Sedimentlängsprofil der Elbe, GDCh-Tagung 1997 in Lindau

Galassi S, Benfenati E (2000) Fractionation and toxicity evaluation of waste waters. J Chromatogr A 889:149-54.

Giesy JP, Kannan K (2002) Perfluorochemical surfactants in the environment. Environ Sci Technol 36:146A-152A

Ginn TC, Pastorok RA (1992) Assessment and mangement of contaminated sediments in Puget Sound. In: Burton GA (ed), Sediment toxicity assessment. Lewis, Boca Raton, pp. 371-401

Gratzer H, Ahlf W (1999a) Erarbeitung von Kriterien zur Ableitung von Qualitätszielen für Sedimente und Schwebstoffe. UBA-Texte 44/99:171

Gratzer W, Ahlf W (1999b) Ökotoxikologische Untersuchung von Feststoffen und Lösungen mit Caenorhabditis elegans (Nematoda) als Testorganismus. In: DVWK, Kern U, Westrich B (Hrsg), Methoden zur Erkundung, Untersuchung und Bewertung von Sedimentablagerungen und Schwebstoffen in Gewässern. DVWKSchriften, Band 128. Kommissionsbetrieb Wirtschafts- und Verlagsgesellschaft Gas und Wasser mbH, Bonn, pp. 246-251

Grifoll M, Solanas AM, Bayona JM (1990) Characterization of genotoxic components in sediments by mass spectrometric techniques combined with Salmonella/microsome test. Arch Environ Contam Toxicol 19:175-184

Grund S, Hecker M, Keiter S, Higley E, Gracia TR, Schönberger R, Rastall A, Erdinger L, Suter M, Braunbeck T, Giesy JP, Hollert H (2009a) Alteration of steroidogenesis and changes in the production of different steroid hormons in H295R cells exposed to sediment extracts of the Danube river (Germany). To be submitted to Aquatic Toxicology

Grund S, Keiter S, Böttcher M, Seitz N, Wurm K, Manz W, Hollert H, Braunbeck T (2009b) Assessment of fish health status in the Upper Danube river by investigation of ultrastructural alterations in the liver of barbel (Barbus barbus, L.) and its correlation to sediment quality. Ecology of Freshwater Fish, submitted

Gunkel G (1994) Bioindikation in aquatischen Ökosystemen. Gustav Fischer Verlag, Jena, Stuttgart, $540 \mathrm{pp}$

Hallare AV, Kosmehl T, Schulze T, Hollert H, Kohler HR, Triebskorn R (2005) Assessing contamination levels of Laguna Lake sediments (Philippines) using a contact assay with zebrafish (Danio rerio) embryos. Sci Total Environ 347:254-71

Harkey GA, Landrum PF, Klaine SJ (1994) Comparison of wholesediment, elutriate and pore-water exposures for use in assessing sediment-associated organic contaminants in bioassays. Environ Toxicol Chem 13:1315-1329

Heise S, Förstner U (2006) Risks from Historical Contaminated Sediments in the Rhine Basin. Water Air Soil Poll 6:625-636

Henschel T, Traunsburger W, Ahlf W, Fenn B, Popp W, Kopf W, Steinberg C (1997) Die Karower Teiche in Berlin, Nachklärbecken im Abwasserrieselfeldbetrieb: Bewertung des ökotoxikologischen Wirkpotentials sedimentgebundener Schadstoffe mit einer Batterie von Biotests, 2. Jahrestagung der SETAC-German Language Branch, Aachen

Henschel T, Ahlf W, Calmano W, Krebs F, Maaß V (2001) Teil III-Gefährdungsabschätzung v. Gewässersedimenten - Handlungsempfehlungen und Bewertungsvorschläge. In: Calmano W (Hrsg), Untersuchung und Bewertung von Sedimenten: ökotoxikologische und chemische Testmethoden. Springer, Heidelberg, pp 465-544

Hill IR, Matthiessen P, Heimbach F (1993) Guidance document on sediment toxicity tests and bioassays for freshwater and marine environments. In: Hill IR, Matthiessen P, Heimbach F (Hrsg.), 
Workshop on sediment toxicity assessment. Society of Environmental Toxicology and Chemistry, Netherlands

Hilscherova K, Dusek L, Kannan K, Giesy JP, Holoubek I (2000) Evaluation of cytotoxicity, dioxin-like activity and estrogenicity of complex environmental mixtures. Cent Eur J Public Health 8(Suppl):28-29

Ho KTY, Quinn JG (1993a) Bioassay-directed fractionation of organic contaminants in an estuarine sediment using the new mutagenic bioassay, Mutatox. Environ Tox Chem 12:823-830

Ho KTY, Quinn JG (1993b) Physical and chemical parameters of sediment extraction and fractionation that influence toxicity as evaluated by Microtox. Environ Toxicol Chem 12:615-625

Ho KTY, McKinney RA, Kuhn A, Pelletier MC, Burgess RM (1997) Identification of acute toxicants in New Bedford Harbor sediments. Environ Toxicol Chem. 16:551-558

Hollert H (2001) Entwicklung eines kombinierten Untersuchungssystems für die Bewertung der ökotoxikologischen Belastung von Fließgewässersedimenten und -schwebstoffen. Dissertation, Fakultät für Biologie der Universität Heidelberg, Als pdf-Dokument online unter: http://www.ub.uni-heidelberg.de/archiv/1602, 258

Hollert H, Braunbeck T (1997) Ökotoxikologie in vitro - Gefährdungspotential in Wasser, Sediment und Schwebstoffen. Veröff. PAÖ, 21. Landesanstalt für Umweltschutz Baden-Württemberg, Karlsruhe, $189 \mathrm{pp}$

Hollert H, Dürr M, Erdinger L, Braunbeck T (1998) Wie giftig sind Schwebstoffe und Sedimente des Neckars? Zur Eignung von Biotests und Bioassay-dirigierten Fraktionierungstechniken für die Bewertung des Schadstoffpotentials in hydrologischen Fallstudien. In: Karrasch H, Gamerith W, Schwan T, Sachs K, Krause U (Hrsg), HGG-Journal 13, Heidelberg, pp. 130-145

Hollert H, Dürr M, Geier V, Erdinger L, Braunbeck T (1999a) Ökotoxikologie in vitro: Gefährdungspotential von Neckarsedimenten. In: Oehlmann J, Markert B (Hrsg), Ökosystemare Ansätze in der Ökotoxikologie. Ecomed-Verlag, Stuttgart, pp. 444-462

Hollert H, Dürr M, Islinger M, Erdinger L, Braunbeck T (1999b) Biotestverfahren zur Bestimmung des zelltoxischen Schädigungspotentials von Sedimenten und Schwebstoffen. In: DVWK, Kern U, Westrich B (Hrsg), Methoden zur Erkundung, Untersuchung und Bewertung von Sedimentablagerungen und Schwebstoffen in Gewässern. DVWK-Schriften, Band 128. Kommissionsbetrieb Wirtschafts- und Verlagsgesellschaft Gas und Wasser mbH, Bonn, pp. 256-261

Hollert H, Dürr M, Karaus U, Siebert I, Winn N, Islinger M, Schöler H, Gratzer H, Holtey-Weber R, Färber H, Ahlf W, Erdinger L, Braunbeck T (1999c) Integrated sediment assessment in the Neckar catchment area (Germany) with analysis of in vitro toxicity, chemistry and macrozoobenthos. Annual Meeting of the Society of Environmental Toxicology and Chemistry, Leipzig

Hollert H, Dürr M, Karaus U, Siebert I, Winn N, Pawlowski S, Islinger M, Gratzer H, Ahlf W, Karrasch H, Erdinger L, Braunbeck T (1999d) Identifizierung und Bewertung (öko)toxikologisch belasteter Gewässer in Baden-Württemberg. Berichte Umweltforschung des Forschungszentrums Karlsruhe, online unter www.fzk.de

Hollert H, Dürr M, Winn N, Islinger M, Holtey-Weber R, Färber H, Haag I, Kern U, Karrasch H, Erdinger L, Braunbeck T (1999e) Risk Assessment of a flood event, Part 1: Cyto-, genotoxicity and enodocrine-disrupting potential of suspended matter, Annual Meeting of the Society of Environmental Toxicology and Chemistry, Leipzig

Hollert H, Gratzer H, Ahlf W, Braunbeck T (1999f) Einleitung-Kapitel Ökotoxikologie. In: DVWK, Kern U, Westrich B (Hrsg), Methoden zur Erkundung, Untersuchung und Bewertung von Sedimentablagerungen und Schwebstoffen in Gewässern. DVWKSchriften, Band 128. Kommissionsbetrieb Wirtschafts- und Verlagsgesellschaft Gas und Wasser mbH, Bonn, pp. 36-51

Hollert H, Islinger M, Siebert I, Pawlowski S, Braunbeck T (1999g) Bestimmung des östrogen wirksamen Potentials von Sedimenten und Schwebstoffen mit hilfe eines Vitellogenin-mRNA-Assays. In: DVWK, Kern U, Westrich B (Hrsg), Methoden zur Erkundung, Untersuchung und Bewertung von Sedimentablagerungen und Schwebstoffen in Gewässern. DVWK-Schriften, Band 128. Kommissionsbetrieb Wirtschafts- und Verlagsgesellschaft Gas und Wasser mbH, Bonn, pp. 290-296

Hollert H, Dürr M, Erdinger L, Braunbeck T (2000) Cytotoxicity of settling particulate matter (SPM) and sediments of the Neckar river (Germany) during a winter flood. Environ Toxicol Chem 19:528-534

Hollert H, Dürr M, Olsman H, Halldin K, Bavel Bv, Brack W, Tysklind M, Engwall M, Braunbeck T (2002a) Biological and chemical determination of dioxin-like compounds in sediments by means of a sediment triad approach in the catchment area of the Neckar River. Ecotoxicology 11:323-336

Hollert H, Heise S, Pudenz S, Brüggemann R, Ahlf W, Braunbeck T (2002b) Application of a sediment quality triad and different statistical approaches (hasse diagrams and fuzzy logic) for the comparative evaluation of small streams. Ecotoxicology 11: 311-321

Hollert H, Haag I, Dürr M, Wetterauer B, Holtey-Weber R, Kern U, Westrich B, Färber H, Erdinger L, Braunbeck T (2003a) Investigations of the ecotoxicological hazard potential and risk of erosion of contaminated sediments in lock-regulated rivers. Umweltwiss Schadst Forsch 15:5-12

Hollert H, Haag I, Dürr M, Wetterauer B, Holtey-Weber R, Kern U, Westrich B, Färber H, Erdinger L, Braunbeck T (2003b) Untersuchungen zum ökotoxikologischen Schädigungspotenzial und Erosionsrisiko von kontaminierten Sedimenten in staugeregelten Flüssen. Umweltwiss Schadst Forsch 15:5-12

Hollert H, Keiter S, König N, Rudolf M, Ulrich M, Braunbeck T (2003c) A New Sediment Contact Assay to Assess Particle-bound Pollutants Using Zebrafish (Danio rerio) Embryos. J Soils Sediments 3:197-207

Hollert H, Dürr M, Holtey-Weber R, Islinger M, Brack W, Färber H, Erdinger L, Braunbeck T (2005) Endocrine disruption of water and sediment extracts in a non-radioactive dot blot/RNAse protection-assay using isolated hepatocytes of rainbow trout-How explain deficiencies between bioanalytical effectiveness and chemically determined concentrations? Environ Sci Poll Res $12: 347-360$

Hollert H, Dürr M, Haag I, Wölz J, Hilscherova K, Blaha L, Gerbersdorf S (2007a) Influence of hydrodynamics on sediment ecotoxicity. In: Westrich B, Foerstner U (Hrsg), Sediment hydraulics and pollutant mobility in rivers. Springer-Verlag, Heidelberg, pp. 401-416

Hollert H, Heise S, Keiter S, Heininger P, Förstner U (2007b) Wasserrahmenrichtlinie - Fortschritte und Defizite. Umweltwiss Schadst Forsch 19:58-70

Hollert H, Seiler TB, Blaha L, Young AL (2007c) Multiple stressors for the environment: Present and future challenges and perspectives. Environ Sci Poll Res 14:222-222

Hulme M, Jenkins G, Lu X, Turnpenny J, Mitchell TD, Jones RG, Lowe J, Murphy J, Hassell D, Boorman P, S MRaH (2002) Climate Change Scenarios for the United Kingdom: The UKCIP02 Scientific Report, Tyndall Centre for Climate Change Research, School of Environmental Sciences, University of East Anglia, Norwich, UK

Ikeda T, Yoshitani J, Terakawa A (2005) Flood management under climatic variability and its future perspective in Japan. Water Sci Technol 51:133-40

Ingersoll CG (1995) Sediment tests. In: Rand GM (ed), Fundamentals of Aquatic Toxicology. Taylor and Francis, Washington D. C., pp 231-256

Ingersoll CG, Ankley GT, Benoit DA, Brunson EL, Burton GA, Dwyer FJ, Hoke RA, Landrum PF, Norberg-King TJ, Winger PV (1995) Toxicity and bioaccumulation of sediment-associated contami- 
nants using freshwater invertebrates: A review of methods and applications. Environ Tox Chem 14:1885-1894

Ingersoll CG, Dillon T, Biddinger GR (1997) Ecological risk assessment of contaminated sediments. SETAC Special Publication Series. SETAC-Press, Pensacola, Florida, 389 pp

Jarvis AS, Honeycutt ME, McFarland VA, Bulich AA, Bounds HC (1996) A comparison of the Ames assay and Mutatox in assessing the mutagenic potential of contaminated dredged sediment. Ecotox Environ Safety 33:193-200

Karbe L, Mädler K, Janský B (1992) Biologische Effekte von Schadstoffen und toxisches Potential von Wasser und Sediment in Elbe und Nordsee - Statusseminar zum Biotox-Programm. Berichte aus dem Zentrum für Meeres- und Klimaforschung der Universität Hamburg, 24, Hamburg, 69 pp

Karbe L, Mädler K, Westendorf J (1994) Biologische Effekte von Schadstoffen und toxisches Potential von Wasser und Sediment in der Elbe und Nordsee (Biotox Elbe/Biotox Nordsee II) - Statusseminar am 7. Januar 1994. Berichte des Zentrums für Meeresund Klimaforschung-Reihe E, 7, Hamburg, 151 pp

Kay AL, Jones RG, Reynard NS (2006) RCM rainfall for UK flood frequency estimation. II. Climate change results. Journal of Hydrology 318:163-172

Keiter S, Rastall A, Kosmehl T, Wurm K, Erdinger L, Braunbeck T, Hollert H (2006) Ecotoxicological assessment of sediment, suspended matter and water samples in the upper Danube River. A pilot study in search for the causes for the decline of fish catches. Environ Sci Pollut Res 13:308-19

Keiter S, Grund S, van Bavel B, Hagberg J, Engwall M, Kammann U, Klempt M, Manz W, Olsman H, Braunbeck T, Hollert H (2008) Activities and identification of aryl hydrocarbon receptor agonists in sediments from the Danube river. Anal Bioanal Chem 390:2009-19

Keiter S, Böttcher M, Grund S, Seitz N, Braunbeck T, Hollert H (2009) Der Fischrückgang in der oberen Donau. Umweltwiss Schadst Forsch 21(2), DOI:10.1007/s12302-009-0040-x

Kemble NE, Brumbaugh WG, Brunson EL, Dwyer FJ (1994) Toxicity of metal-contaminated sediments from the upper Clark Fork River, Montana, to aquatic invertebrates and fish in laboratory exposures. Environ Tox Chem 13:1985-1997

Khim JS, Villeneuve DL, Kannan K, Koh CH, Giesy JP (1999a) Characterization and distribution of trace organic contaminants in sediment from Masan Bay, Korea. 2. In vitro gene expression assays. Environ Sci Technol 33:4206-4211

Khim JS, Villeneuve DL, Kannan K, Lee KT, Snyder SA, Koh CH, Giesy JP (1999b) Alkylphenols, polycyclic aromatic hydrocarbons, and organochlorines in sediment from Lake Shihwa, Korea: Instrumental and bioanalytical characterization. Environ Tox Chem 18:2424-2432

Koethe H (2003) Existing sediment management guidelines: An overview. What will happen with the sediment/dredged material? J Soils Sediments 3:139-143

Kosmehl T, Krebs F, Manz W, Erdinger L, Braunbeck T, Hollert H (2004) Comparative genotoxicity testing of Rhine river sediment extracts using the permanent cell lines RTG-2 and RTL-W1 in the comet assay and Ames assay. J Soils Sediments 4:84-94

Kosmehl T, Krebs F, Manz W, Braunbeck T, Hollert H (2007) Differentiation between bioavailable and total hazard potential of sediment-induced DNA fragmentation as measured by the comet assay with zebrafish embryos. J Soils Sediments 7:377-387

Kosmehl T, Hallare AV, Braunbeck T, Hollert H (2008) DNA damage induced by genotoxicants in zebrafish (Danio rerio) embryos after contact exposure to freeze-dried sediment and sediment extracts from Laguna Lake (The Philippines) as measured by the comet assay. Mutat Res 650:1-14

Kostanjsek R, Lapanje A, Drobne D, Perovic S, Perovic A, Zidar P, Strus J, Hollert H, Karaman G (2005) Bacterial community struc- ture analyses to assess pollution of water and sediments in the Lake Shkodra/Skadar, Balkan Peninsula. Environ Sci Pollut Res 12:361-368

Krebs F (1999) Ökotoxikologische Klassifizierung von Sedimenten mit Hilfe der pT-Wert-Methode. In: DVWK, Kern U, Westrich B (Hrsg), Methoden zur Erkundung, Untersuchung und Bewertung von Sedimentablagerungen und Schwebstoffen in Gewässern. DVWK-Schriften, Band 128. Kommissionsbetrieb Wirtschafts- und Verlagsgesellschaft Gas und Wasser mbH, Bonn, pp 297-303

Kwan KK, Dukta BJ (1990) Simple two-step sediment extraction procedure for the use in genotoxicity and toxicity. Tox Assess $5: 395-404$

La Point TW, Fairchild JF (1992) Evaluation of sediment contaminant toxicity: the use of freshwater community structure. In: Burton GA (ed), Sediment toxicity assessment. Lewis-Publishers, Boca Raton, pp 87-110

Landolt ML, Kocan RM (1984) Lethal and sublethal effects of marine sediment extracts on fish cells and chromosomes. Helgoländer Meeresuntersuchungen 37:479-491

Legler J (2001) Development and application of in vitro and in vivo reporter gene assays for the assessment of (xeno-)estrogenic compounds in the aquatic environment, $132 \mathrm{pp}$

Long ER (2000) Degraded sediment quality in US estuaries: A review of magnitude and ecological implications. Ecological Applications 10:338-349

Lubcke-von Varel U, Streck G, Brack W (2008) Automated fractionation procedure for polycyclic aromatic compounds in sediment extracts on three coupled normal-phase high-performance liquid chromatography columns. J Chromatogr A 1185:31-42

Luque-Garcia JL, de Castro MDL (2003) Extraction of polychlorinated biphenyls from soils by automated focused microwave-assisted Soxhlet extraction. J Chromatogr A 998:21-29

Luque-Garcia JL, de Castro MDL (2004) Focused microwave-assisted Soxhlet extraction: devices and applications. Talanta 64:571-577

Machala M, Vonrácek J, Bláha L, Staffová K, Kozubík A, Hofmanová J, Minksová K, Cupr P, Hrdlicka A, Neca J, Ulrich R, Holoubek I (1998) Cellular and biochemical indices for in vitro evaluation of toxicity of organic extracts from river sediments, Jahrestagung der SETAC-Europe, Bordeaux, pp. 3C/P36

Maier M, Kuehlers D, Brauch H-J, Fleig M, Maier D, Jirka GH, Mohrlock U, Bethge E, Bernhart HH, Lehmann B, Hillebrand G, Wölz J, Hollert H (2005) RIMAX-Verbundprojekt HoT - Spannungsfeld Hochwasserrückhaltung und Trinkwasserversorgung: Vermeidung von Nutzungskonflikten. Umweltwiss Schadst Forsch 17:248-249

Maruoka S, Yamanaka S, Yamamoto Y (1986) Isolation of mutagenic components by high- performance liquid chromatography from XAD extract of water from the Nishitakase river, Kyoto City, Japan. Sci Total Environ 57:29-38

Mudroch A, MacKnight SD (1994a) Bottom sediment sampling. In: Mudroch A, MacKnight SD (eds), Handbook of techniques for aquatic sediments sampling. Lewis Publishers, Boca Raton, pp 29-96

Mudroch A, MacKnight SD (1994b) Handbook of techniques for aquatic sediments sampling. Lewis Publishers, Boca Raton, $236 \mathrm{pp}$

Nagel R (2002) DarT: The embryo test with the Zebrafish Danio rerio - a general model in ecotoxicology and toxicology. Altex 19(Suppl 1):38-48

Netzband A, Brils J, Brauch HJ, Liska I, Miloradov M, Nachtnebel HP, Pirker O, Rast G, Almodovar M, Dias EB, Gomes FV, Heise S, Portela L, Vale C, Forstner U, Gabriel T, Heininger P, Sassen K, Schulz S, Brien J, Morris R, Owens P, White S, Whitehead P, Winn P, den Besten P, Della Sala S, Eisma M, Hauge A, Keller M, Slob A (2007) Sediment management: An essential element of river basin management plans. J Soils Sediments 7:117-132 
Neumann-Hensel H, Ricking M, Hollert H, Ahlf W (2000a) Empfehlung zur Bewertung von Sedimentbelastungen. Bodenschutz 3:111-117

Neumann-Hensel H, Ricking M, Hollert H, Ahlf W, unter Mitarbeit von Lay J-P, Terytze K (2000b) Handlungsanleitung zur Gewässerbeurteilung anhand der Sedimentkontamination. Deutsche Bundesstiftung Umwelt und Umweltbundesamt

Norrgren L, Brunström B, Engwall M, Mwase M (1998) Biological impact of lipophilic sediment extracts from the Kafue River, Sambia, in microinjected rainbow trout yolk-sac fry and chick embryo livers exposed in vitro. Aquatic Ecosystem Health and Management 1:91-99

Oetken M, Stachel B, Pfenninger M, Oehlmann J (2005) Impact of a flood disaster on sediment toxicity in a major river system-the Elbe flood 2002 as a case study. Environ Pollut 134:87-95

Otte JC, Andersson C, Abrahamson A, Olsman H, Keiter S, Engwall M, Hollert H, Brunstrom B (2008) A bioassay approach to determine the dioxin-like activity in sediment extracts from the Danube River: ethoxyresorufin-O-deethylase induction in gill filaments and liver of three-spined sticklebacks (Gasterosteus aculeatus L.). Environ Int 34:1176-84

Otto D, Lindström-Seppä P, Sen C (1994) Cytochrome P450-dependent enzymes and oxidant-mediated responses in rainbow trout exposed to contaminated sediments. Ecotoxicol Environ Safety 27:265-280

Power EA, Chapman PM (1992) Assessing sediment quality. In: Burton GA (ed), Sediment toxicity assessment. Lewis-Publishers, Boca Raton, pp. 1-18

Puglisi E, Patterson CJ, Paton GI (2003) Non-exhaustive extraction techniques (NEETs) for bioavailability assessment of organic hydrophobic compounds in soils. Agronomie 23:755-756

Puglisi E, Murk AJ, van den Bergt HJ, Grotenhuis T (2007) Extraction and bioanalysis of the ecotoxicologically relevant fraction of contaminants in sediments. Environ Tox Chem 26:2122-2128

Reemtsma T, Fiehn O, Jekel M (1999) A modified method for the analysis of organics in industrial wastewater as directed by their toxicity to Vibrio fischeri. Fres J Analytical Chemistry 363:771-776

Reid BJ, Stokes JD, Jones KC, Semple KT (2000) Nonexhaustive cyclodextrin-based extraction technique for the evaluation of PAH bioavailability. Environ Sci Technol 34:3174-3179

Reifferscheid G, Ziemann C, Fieblinger D, Dill F, Gminski R, Grummt HJ, Hafner C, Hollert H, Kunz S, Rodrigo G, Stopper $\mathrm{H}$, Selke D (2008) Measurement of genotoxicity in wastewater samples with the in vitro micronucleus test: results of a roundrobin study in the context of standardisation according to ISO. Mutat Res 649:15-27

Reynoldson TB, Day KE (1993) Freshwater sediments. In: Calow P (ed), Handbook of Ecotoxicology. Blackwell Scientific Publications, Oxford, pp 83-100

Rönnpagel K, Neumann-Hensel H, Ahlf W (1999) Kontakttest für Feststoffe mit Arthrobacter globiformis. In: DVWK, Kern U, Westrich B (eds), Methoden zur Erkundung, Untersuchung und Bewertung von Sedimentablagerungen und Schwebstoffen in Gewässern. DVWK-Schriften, Band 128. Kommissionsbetrieb Wirtschafts- und Verlagsgesellschaft Gas und Wasser mbH, Bonn, pp. 252-255

Salomons W (2005) Sediments in the Catchment-coast Continuum. J Soils Sediments 5:2-8

Samolloff MR, Bell J, Birkholz DA, Webster GRB, Arnott EG, Pulak R, Madrid A (1983) Combined bioassay-chemical fraction scheme for the determination and ranking of toxic chemicals in sediments. Environ Sci Technol 17:329-334

Schnurstein A, Froschauer A, Tischmeyer A, Braunbeck T (1999) Die Einzelzellgelelektophorese (Comet-Assay) zum Nachweis des gentoxischen Potentials von Umweltproben. In: DVWK, Kern U, Westrich B (Hrsg), Methoden zur Erkundung, Untersuchung und
Bewertung von Sedimentablagerungen und Schwebstoffen in Gewässern. DVWK-Schriften, Band 128. Kommissionsbetrieb Wirtschafts- und Verlagsgesellschaft Gas und Wasser $\mathrm{mbH}$, Bonn, pp 274-281

SedNet (2004) Sediment, a valuable resource that needs Europe's attention; SedNet recommendations for sediment research priorities related to the soil research clusters. http://www.sednet.org/ materiale/Sediment a valuable resource.pdf

Seiler TB, Rastall AC, Leist E, Erdinger L, Braunbeck T, Hollert H (2006) Membrane dialysis extraction (MDE) A novel approach for extracting toxicologically relevant hydrophobic organic compounds from soils and sediments for assessment in biotests. J Soils Sediments 6:20-29

Seiler TB, Schulze T, Hollert H (2008) The risk of altering soil and sediment samples upon extract preparation for analytical and bio-analytical investigations - a review. Anal Bioanal Chem 390:1975-1985

Seitz N, Bottcher M, Keiter S, Kosmehl T, Manz W, Hollert H, Braunbeck T (2008) A novel statistical approach for the evaluation of comet assay data. Mutat Res 652:38-45

Semple KT, Morriss AWJ, Paton GI (2003) Bioavailability of hydrophobic organic contaminants in soils: fundamental concepts and techniques for analysis. Europ J Soil Sci 54:809-818

Staffová K, Kannan K, Giesy JP, Holoubek I, Ansorgova A, Machala M (1998) In vitro bioassays in assessment of AhR and ERmediated activity of samples from rivers in the Czech Republic, Jahrestagung der SETAC-Europe, Bordeaux, pp. 3C/P011

Strmac M (1999) Ökotoxikologische Untersuchung und Bewertung verschiedener Kompartimente in kleinen Fließgewässern mit Hilfe von Zellkulturen sowie Embryonen und Larven des Zebrabärblings (Danio rerio). Dissertation, Fakultät für Biologie der Universität Heidelberg, $216 \mathrm{pp}$

Strmac M, Braunbeck T (2000) Isolated hepatocytes of rainbow trout (Oncorhynchus mykiss) as a tool to discriminate between differently contaminated small river systems. Toxicol In Vitro 14: 361-77

Strmac M, Oberemm A, Braunbeck T (2002) Assessment of sediment toxicity to early life stages of fish: effects of sediments from differently polluted small rivers on zebrafish (Danio rerio) embryos and larvae. J Fish Biol 61:24-38

Traunspurger W, Drews C (1996) Toxicity analysis of freshwater and marine sediments with meio- and macrobenthic organisms: A review. Hydrobiologia 328:215-261

True CJ, Heyward AA (1990) Relationships between Microtox test results, extraction methods, and physical and chemical compositions of marine sediment samples. Tox Assess 5:29-45

Ulrich M, Schulze T, Leist E, Glaß B, Maier M, Maier D, Braunbeck T, Hollert H (2002) Ökotoxikologische Untersuchung von Sedimenten und Schwebstoffen: Abschätzung des Gefährdungspotenzials für Trinkwasser und Korrelation verschiedener Expositionspfade (Acetonischer Extrakt, Natives Sediment) im Bakterienkontakttest und Fischeitest. Umwelwiss Schadst Forsch 14:132-137

Vahl HH, Karbe L, Westendorf J (1997) Genotoxicity assessment of suspended particulate matter in the Elbe river: comparison of Salmonella microsome test, arabinose resistance test, and umu-test. Mut Res 394:81-93

van Beelen P (2003) A review on the application of microbial toxicity tests for deriving sediment quality guidelines. Chemosphere 53:795-808

van Beelen P, Doelman P (1997) Significance and application of microbial toxicity tests in assessing ecotoxicological risks of contaminants in soil and sediment. Chemosphere 34:455-499

Wang (1999) Porewater toxicity testing: does it make sense? SETACEurope News 10:6-7

Wenning R, Ingersoll C (2002) Summary of the SETAC Pellston Workshop on Use of Sediment Quality Guidelines and Related Tools 
for the Assessment of Contaminated Sediments;. 17-22 August 2002; Fairmont, Montana, USA. Society of Environmental Toxicology and Chemistry (SETAC). Pensacola FL, USA. online: http://www.setac.org/files/SQGSummary.pdf

West WR, Smith PA, Booth GM, Wise SA, Lee ML (1986) Determination of genotoxic polycyclic aromatic hydrocarbons in a sediment from the Black River (Ohio). Arch Environ Contam Toxicol 15:241-249

Westrich B, Foerstner U (2007) Sediment Dynamics and Pollutant Mobility in Rivers. Springer, Heidelberg, $430 \mathrm{pp}$

Westrich B, Li C, Hammer D, Förstner U (2007) Requirement on sediment data quality-Hydrodynamics and pollutant mobility in rivers. In: Westrich B, Förstner U (Hrsg), Sediment dynamics and pollutant mobility in rivers. Springer, Heidelberg, pp 49-65

White PA, Rasmussen JB, Blaise C (1998a) Genotoxic substances in the St. Lawrence system I: Industrial genotoxins sorbed to particulate matter in the St. Lawrence, St. Maurice, and Saguenay Rivers, Canada. Environ Tox Chem 17:286-303

White PA, Rasmussen JB, Blaise C (1998b) Genotoxic substances in the St. Lawrence system II: Extracts of fish and macroinvertebrates from the St. Lawrence and Saguenay Rivers, Canada. Environ Tox Chem 17:304-316
Wilby RL, Orr HG, Hedger M, Forrow D, Blackmore M (2006) Risks posed by climate change to the delivery of Water Framework Directive objectives in the UK. Environ Int 32:1043-1055

Wölz J, Engwall M, Maletz S, Olsman Takner H, van Bavel B, Kammann U, Klempt M, Weber R, Braunbeck T, Hollert H (2008) Changes in toxicity and $\mathrm{Ah}$ receptor agonist activity of suspended particulate matter during flood events at the rivers Neckar and Rhine - a mass balance approach using in vitro methods and chemical analysis. Environ Sci Pollut Res 15:536-53

Wölz J, Cofalla C, Hudjetz S, Roger S, Brinkmann M, Lennartz F, Schmidt B, Schäffer A, Kammann U, Hecker M, Schüttrumpf H, Hollert H (2009) In search of the ecological and toxicological relevance of sediment re-mobilization and transport during flood events-the joint research project FLOODSEARCH. J Soils Sediments $2: 1-5$

Wurm K (2001) Untersuchung zum Rückgang des fischereilichen Ertrages in der Donau zwischen Sigmaringen und Erbach, Gewässerökologisches Labor, Tübingen

Zimmer M, Ahlf W 1994: Erarbeitung von Kriterien zur Ableitung von Qualitätszielen für Sedimente und Schwebstoffe. Texte 69/94, Technische Universität Hamburg-Harburg, Berlin 